\title{
Chronic Cocaine-Induced H3 Acetylation and Transcriptional Activation of CaMKIl $\alpha$ in the Nucleus Accumbens Is Critical for Motivation for Drug Reinforcement
}

\author{
Lei Wang ${ }^{1,2}$, Zhigang Lv',2, Zhaoyang Hu', Jian Sheng', Bin Hui', Jie Sun' and Lan Ma*,' \\ 'Pharmacology Research Center and the State Key Laboratory of Medical Neurobiology, Shanghai Medical College and Institutes of Brain \\ Science, Fudan University, Shanghai, China
}

\begin{abstract}
The regulation of gene expression in the brain reward regions is known to contribute to the pathogenesis and persistence of drug addiction. Increasing evidence suggests that the regulation of gene transcription is mediated by epigenetic mechanisms that alter the chromatin structure at specific gene promoters. To better understand the involvement of epigenetic regulation in drug reinforcement properties, rats were subjected to cocaine self-administration paradigm. Daily histone deacetylase (HDAC) inhibitor infusions in the shell of the nucleus accumbens (NAc) caused an upward shift in the dose-response curve under fixed-ratio schedule and increased the break point under progressive-ratio schedule, indicating enhanced motivation for self-administered drug. The effect of the HDAC inhibitor is attributed to the increased elevation of histone acetylation induced by chronic, but not acute, cocaine experience. In contrast, neutralizing the chronic cocaine-induced increase in histone modification by the bilateral overexpression of HDAC4 in the NAc shell reduced drug motivation. The association between the motivation for cocaine and the transcriptional activation of addiction-related genes by $\mathrm{H} 3$ acetylation in the NAc shell was analyzed. Among the genes activated by chronic cocaine experiences, the expression of CaMKIl $\alpha$, but not $C a M K I I \beta$, correlated positively with motivation for the drug. Lentivirus-mediated shRNA knockdown experiments showed that $\mathrm{CaMKIl} \alpha$, but not CaMKII $\beta$, in the NAc shell is essential for the maintenance of motivation to self-administered cocaine. These findings suggest that chronic drug-use-induced transcriptional activation of genes, such as CaMKIl $\alpha$, modulated by $\mathrm{H} 3$ acetylation in the $\mathrm{NAc}$ is a critical regulatory mechanism underlying motivation for drug reinforcement.
\end{abstract}

Neuropsychopharmacology (2010) 35, 913-928; doi: I0.1038/npp.2009.193; published online 9 December 2009

Keywords: histone acetylation; nucleus accumbens; motivation; cocaine self-administration; addiction; CaMKIl $\alpha$

\section{INTRODUCTION}

Drug addiction is a debilitating psychiatric disorder characterized by (1) a compulsion to seek and take the drug, (2) a loss of control in limiting intake, and (3) the emergence of a negative emotional state when access to the drug is prevented (Hyman et al, 2006; Kalivas et al, 2005; Koob and Kreek, 2007). The complex behavioral changes leading to drug addiction are thought to result from molecular and cellular adaptation in specific brain regions (Brami-Cherrier et al, 2005). One area of intensive research to clarify neuroadaptation addresses the regulation of gene expression induced by the drug (Nestler, 2001). The drug induces changes in gene expression in key brain reward regions, such as the nucleus accumbens (NAc),

*Correspondence: Professor L Ma, Pharmacology Research Center, Fudan University, 138 Yixueyuan Road, Shanghai, Shanghai 200032, China, Tel: +86 215423 7522, Fax: + 862154237621 ,

E-mail: lanma@fudan.edu.cn

${ }^{2}$ These authors contributed equally to this work.

Received 10 August 2009; revised I October 2009; accepted 2 November 2009 prefrontal cortex (PFC), and ventral tegmental area (VTA). For instance, the expression of the immediate early gene $c$-Fos and several other Fos family proteins is upregulated in the nucleus accumbens, striatum (Courtin et al, 2006) and frontal cortex (Thiriet et al, 2000) after acute cocaine treatment. The expression of genes, such as $A G S 3$, FosB, and BDNF, is induced after chronic cocaine administration (Bowers et al, 2004; Grimm et al, 2003; Nestler et al, 1999; Pich et al, 1997).

Chromatin remodeling epigenetically controls gene transcription, indicating that complex mechanisms regulate the accessibility of genes to the transcriptional machinery (Colvis et al, 2005). In general, increased histone acetylation is associated with DNA relaxation and elevated transcriptional activity, whereas decreased acetylation, brought about by histone deacetylases (HDACs) and methyl-CpGbinding proteins, results in tighter DNA coiling and gene silencing. Histone acetylation/deacetylation is increasingly recognized as a crucial mechanism in several important phenomena in the brain, including neuronal differentiation (Hsieh and Gage, 2004; Lunyak et al, 2002), neurodegeneration (Hockly et al, 2003; Hoshino et al, 2003; Steffan et al, 
2001), circadian rhythm (Etchegaray et al, 2003), seizure (Huang et al, 2002; Tsankova et al, 2004), memory formation (Guan et al, 2009; Levenson et al, 2004; Levenson and Sweatt, 2005), and drug addiction (Kumar et al, 2005; Levine et al, 2005).

Intravenous drug self-administration, which better models the human syndrome especially the addicted-state changes such as increased motivation for the drug (Renthal and Nestler, 2008), is a useful tool for exploring the neurobiology of drug positive reinforcement in experimental animals (Koob et al, 1989). It has been shown that the vertical upward shift in the dose-response curve obtained under a fixed-ratio schedule of reinforcement reflects the escalation in the hedonic set-point (Ahmed and Koob, 1998), which may be accompanied by increased motivation to take the drug (Paterson and Markou, 2003). A downward shift in the dose-response curve is opposite to changes associated with the development of cocaine addiction (Graham et al, 2007; Robledo and Koob, 1993). The progressive-ratio schedule of reinforcement is considered to reflect the motivation to self-administer a drug with less influence from factors such as drug satiation or tolerance than that observed in fixed-ratio schedule of reinforcement (Paterson and Markou, 2003). However, research is scarce into the epigenetic mechanism of drug self-administration and better models of the human syndrome, especially the addicted-state changes such as the increased incentive to drug reinforcement.

The NAc is well known to mediate the primary reinforcing and psychomotor stimulation of drugs of abuse (Everitt and Robbins, 2005; Ito et al, 2004). The NAc is a heterogenous structure with at least two distinct regions, the shell and core, which may contribute in different ways to drug self-administration. There is strong evidence that the mesolimbic dopamine projection to the NAc shell mediates the response rate-increasing or psychomotor-stimulatory effects of the drug. In contrast, the NAc core mediates the effects of the conditioned reinforcer through its afferent inputs from the limbic cortical structures (Belin and Everitt, 2008; Di Ciano et al, 2008; Everitt and Robbins, 2005; Olmstead et al, 2001; Parkinson et al, 1999).

In this study, the role of histone acetylation in the shell and core of the NAc during the incentive motivation for cocaine after a chronic phase of drug self-administration was examined in rats. Chromatin immunoprecipitation (ChIP) assays were performed to analyze the epigenetic mechanism by which gene transcriptional activity is regulated during chronic cocaine use. Our results establish an important role for the chronic cocaine-induced increase in histone $\mathrm{H} 3$ acetylation and the transcriptional activation of the gene encoding $\mathrm{Ca}^{2+} /$ calmodulin-dependent protein kinase (CaMK) II- $\alpha$ in the shell of the NAc in the motivation for cocaine reinforcement and suggest a new therapeutic mechanism for anti-addiction treatment.

\section{MATERIALS AND METHODS}

\section{Animals \\ Male Sprague-Dawley rats (Shanghai Center of Experimen- tal Animal, Chinese Academy of Sciences) weighing 275-325g were housed and maintained on a 12:12-h}

reverse day/light cycle with free access to food and water. All experiments were conducted in strict accordance with the National Institute of Health Guide for the care and use of laboratory animals.

\section{Drugs}

Cocaine hydrochloride (Qinghai Pharmaceutical Firm) was dissolved in $0.9 \%$ saline to make $4 \mathrm{mg} / \mathrm{ml}$ solution. Trichostatin A (TSA, Sigma) and suberoylanilide hydroxamic acid (SAHA, Alexis) were dissolved in 10\% dimethyl sulfoxide (DMSO, Sigma).

\section{Viral Expression}

Expression plasmids for HDAC4 (kindly provided by Dr Ilona S Skerjanc at University of Western Ontario), $\triangle$ HDAC4, and beta-galactosidase were subcloned into adenovirus; and plasmid-based CaMKII $\alpha$ shRNA and CaMKII $\beta$ shRNA were subcloned into lentivirus. The details of adenovirus and lentivirus cloning and packaging are given in the Supplementary Materials and Methods.

\section{Sucrose Training and Surgery}

To facilitate subsequent acquisition of cocaine self-administration, animals were initially maintained at $85 \%$ original body weight and trained to press a lever for a $45 \mathrm{mg}$ sucrose pellet in operant chambers (Med Associates, Georgia, VT) on fixed-ratio 1 schedule until acquisition criteria were achieved (100 pellets self-administered for 3 consecutive days). Animals were then fed ad libitum for at least 1 day before surgical intravenous catheterization and/or brain cannulation as described previously (Choi et al, 2006; Sun et al, 2008). Rats were anaesthetized with $10 \%$ chloral hydrate. A silastic catheter $(0.04 \mathrm{~cm}$, interior diameter) was inserted $3 \mathrm{~cm}$ into the right jugular vein and the other end was attached to a stainless steel pedestal. Bilateral 27-gauge guide cannulae were implanted in the NAc shell $(+1.7 \mathrm{~mm}$ $\mathrm{A} / \mathrm{P}, \pm 0.8 \mathrm{~mm} \mathrm{M} / \mathrm{L}$, and -6.5 or $5.5 \mathrm{~mm} \mathrm{D} / \mathrm{V})$, NAc core (1.7 $\mathrm{mm} \mathrm{A} / \mathrm{P}, \pm 2.2 \mathrm{~mm} \mathrm{M} / \mathrm{L}$, and -6.0 or $5.0 \mathrm{~mm} \mathrm{D} / \mathrm{V})$, or medial prefrontal cortex (mPFC; $3.2 \mathrm{~mm} \mathrm{~A} / \mathrm{P}, \pm 0.7 \mathrm{~mm}$ $\mathrm{M} / \mathrm{L}$, and $-2.2 \mathrm{~mm} \mathrm{D/V)}$ with level skull according to Paxinos and Watson. Chemical or virus perturbations were delivered through 33-gauge (Plastics One) bilateral infusion cannulae cut to extend 1 or $2 \mathrm{~mm}$ beyond guide cannulae. The stainless steel pedestal was then mounted to the rat's skull followed by dental cement. Catheters were flushed every day with $0.2 \mathrm{ml}$ of saline solution containing heparin $(25 \mathrm{U} / \mathrm{ml})$ and benzylpenicillin $(6400 \mathrm{U} / \mathrm{ml})$. After surgery, animals were subjected to standard postoperative care and were allowed to recover for 7 days before the start of any experiment. The positions of cannulae or the infusion of chemicals were verified by Nissl's staining or tracer diffusion, respectively, as described in the Supplementary Materials and Methods, and Supplementary Figure S1.

\section{Cocaine Self-Administration Procedures}

After 1 week of recovery period, animals were trained to self-administer intravenous injections of cocaine delivered 
over $4 \mathrm{~s}$ (fixed-ratio 1) in 4-h session daily (Sun et al, 2008). Each injection was accompanied by extinction of the house light and presence of combined conditioned cues (CS), including illumination of the stimulus light and simultaneous presence of an audible tone for $20 \mathrm{~s}$. Depression of the inactive lever had no programmed consequences. For behavioral experiments, the response requirement was gradually increased to five lever presses (LPs) per injection (fixed-ratio 5 (FR5)) and training continued until cocaine intake was stabilized (number of total infusions varied $<10 \%$ from the mean of three consecutive sessions). Catheter patency was verified after testing by brief anesthesia with sodium methohexital $(0.1 \mathrm{mg}$ in $0.1 \mathrm{ml})$. In some experiments, the reinforcement contingency was changed to a progressive-ratio schedule similar to that described by McGregor and Roberts (1995). Under this schedule, response requirements for each successive injection increased by progressive increments of the following series (Richardson and Roberts, 1996): 1, 2, 4, 6, 9, 12, 15, $20,25,32,40,50,62$, and so on according to response requirement $=\left(5 \mathrm{e}^{(\text {injection times } \times 0.2)}\right)-5$. The number of cocaine infusions/number of sessions earned or the ratio achieved before a 1-h period of non-reinforcement was scored as the break point. Progressive-ratio schedule training was completed when 3 consecutive days of stable responding ( \pm 2 break points) were obtained.

\section{Microinjection Procedures}

The obturators were removed from the guide cannulae and 33-gauge stainless steel microinjectors were inserted. These microinjectors were cut to a length that extended $1 \mathrm{~mm}$ (HDAC inhibitor infusions) or $2 \mathrm{~mm}$ (virus overexpression) below the guide cannulae and into the NAc shell, NAc core, and mPFC. Microinjections into the lateral septum were made through the same guide cannulae aimed at the shell. Animals received bilateral microinjections of $1.0 \mu \mathrm{l}$ of $165 \mu \mathrm{M}$ TSA at a rate of $0.1 \mu \mathrm{l} / \mathrm{min}$ for $10 \mathrm{~min}$, and a total volume of $2.0 \mu \mathrm{l}$ SAHA $(100 \mu \mathrm{M})$ was constantly delivered at a rate of $0.0083 \mu \mathrm{l} / \mathrm{min}$ for $4 \mathrm{~h}$ by mini-pump. For virusmediated gene transfer, adenovirus or lentivirus was microinjected intracerebral at the rate of $0.1 \mu \mathrm{l} / \mathrm{min}$ for $10 \mathrm{~min}$ in $1.0 \mu \mathrm{l}$. After the microinjections, the stainless steel microinjectors were left in place for $5 \mathrm{~min}$ to allow the solution to diffuse away from the tips of the cannulae.

\section{Western Blotting}

Histone for immunoblotting was prepared as previously described (Levenson et al, 2004). In western blotting analysis, the blots were incubated with IRDye $700 \mathrm{CW}$ or $800 \mathrm{CW}$-conjugated secondary antibody, the infrared fluorescence image was obtained using Odyssey infrared imaging system (Li-Cor Bioscience), the optical density of the bands were quantified using the Image-Pro Plus 5.1 (Media Cybernetics), and the optical density of each $\mathrm{AcH} 3, \mathrm{AcH} 4$, or $\mathrm{CaMKII} \alpha$ and $\mathrm{CaMKII} \beta$ bands were normalized to the optical densities of the corresponding $\mathrm{H} 3, \mathrm{H} 4$, or $\beta$-actin bands, respectively. Data were obtained from at least three independent experiments.

\section{Immunohistochemistry}

Brain sections were incubated overnight at $4{ }^{\circ} \mathrm{C}$ with $\mathrm{AcH} 3$ (rabbit polyclonal, Lys-9/Lys-14, $1 \mu \mathrm{g} / \mathrm{ml}$, Upstate Biotechnology) or AcH4 (rabbit polyclonal, Lys-5/Lys-8/Lys-12/ Lys-16, $2 \mu \mathrm{g} / \mathrm{ml}$, Upstate Biotechnology) antibodies. Slices were then incubated for $1 \mathrm{~h}$ at room temperature with biotinylated goat anti-rabbit antibody $(1: 200$, Vector Laboratories) and processed with avidin-biotinylated horseradish peroxidase complex (Elite ABC kit, Vector Laboratories) for $45 \mathrm{~min}$ at room temperature. The reaction was visualized using diaminobenzidine (DAB, Sigma). Pictures of the regions of interest (the NAc shell, core, or mPFC) were taken with a microscopic CDD camera in $\times 40$ object lens $\left(0.066 \mathrm{~mm}^{2} / \mathrm{graph}\right)$. Quantification of immunoreactive cells was performed with Image-Pro Plus 5.1. In brief, taking into account that the positive cells were defined with nuclear staining above basal background, counts above threshold were taken in a standard frame sample area from the two consecutive sections across both hemispheres per animal, with at least eight animals per group, and these counts were averaged to produce a mean.

\section{Chromatin Immunoprecipitation}

Chromatin immunoprecipitation (ChIP) was performed using the Upstate Biotechnology ChIP kit and following a modified protocol from the manufacturer. In brief, brain tissue was fixed in $1 \%$ formaldehyde and cell lysates were sheared by sonication in 1\% SDS lysis buffer to generate chromatin fragments with an average length of 200-1000 bp. The chromatin was then immunoprecipitated overnight at $4{ }^{\circ} \mathrm{C}$ with antibodies specific to $\mathrm{AcH} 3, \mathrm{AcH} 4$, or an equivalent amount of control IgG. Protein-DNA-antibody complexes were precipitated with protein A-agarose beads for $2 \mathrm{~h}$ at $4{ }^{\circ} \mathrm{C}$. Input or DNA in the complex was subjected to quantitative PCR. Primer pairs for specific promoter regions are shown in the Supplementary Table S3.

\section{Reverse Transcription and Quantitative PCR}

Total RNA was extracted from rat NAc shell with TRIzol (Invitrogen) according to the manufacturer's instructions. Reverse transcription of purified RNA (100 ng of total RNA) was performed using superscript III reverse transcriptase (Invitrogen). The quantification of DNA was performed using real-time PCR, using SYBR ${ }^{\mathrm{R}}$ Premix Ex Taq (Takara) and ROTOR-GENE RG-3000A (Corbett Research). Ct values from each sample were obtained using the operating software of RG-3000A. Relative quantification of amplified template was performed as described by Chakrabarti et al (2002). Each PCR reaction, run in triplicate for each brain sample, was repeated at least twice independently. $\Delta \mathrm{Ct}$ was obtained by normalizing to corresponding control or actin internal control.

\section{Statistical Analysis}

Histone acetylation data were analyzed using one-factor ANOVA, followed by Student-Newman-Keuls post hoc comparisons. Behavioral data were analyzed using two-factor ANOVA with repeated measures on dose or test 
session. Significant interactions were followed by univariate ANOVA at each dose or test session, which was also used for sucrose self-administration data, and followed by Student-Newman-Keuls post hoc tests. All correlations were analyzed with Pearson's correlation test.

\section{RESULTS}

\section{Intra-NAc HDAC Inhibitor Infusions Increase the Motivation for Cocaine Self-Administration}

The effect of daily bilateral NAc shell infusions of the HDAC inhibitor TSA into the NAc shell on cocaine self-administration was examined in rats under a fixed-ratio schedule in which five LPs produced a cocaine injection. The animals were trained to self-administer cocaine $750 \mu \mathrm{g} / \mathrm{kg}$ per injection in daily $4 \mathrm{~h}$ sessions for 3-4 weeks until their cocaine intake had stabilized. The animals then received an intra-NAc-shell infusion of TSA $(165 \mathrm{pmol})$ or vehicle $(10 \%$ DMSO), before training session each day for 5 days. Cocaine self-administration session was carried out for $15 \mathrm{~min}$ after the completion of daily TSA or vehicle infusion. As shown in the left panel of Figure 1a, TSA infusions into the NAc shell had no significant effect on the self-administration of cocaine at $750 \mu \mathrm{g} / \mathrm{kg} / \mathrm{injection}$.

The animals were then tested in a dose-response procedure with descending doses of cocaine $(1000,500$, 300,100 , and $0 \mu \mathrm{g} / \mathrm{kg} /$ injection) under the FR5 schedule, and intracerebral infusions of TSA or vehicle were given as described above. As shown in Figure 1a, cocaine was selfadministered with a bell-shaped dose-response curve, in which the descending limb indicates a prolonged duration of the cocaine reward at higher injection doses. Notably, infusions of TSA into the shell of NAc led to an upward shift in the dose-response curve (treatment by dose interaction, $\left.\mathrm{F}_{4,101}=3.263, P=0.015\right)$. Higher self-administration rates (at the doses of 300 and $500 \mu \mathrm{g} / \mathrm{kg} /$ injection) of TSA-treated animals were observed in the TSA-treated animals compared with those in the vehicle-infused control. TSA also had a significant effect when these dose-response data were transformed into cocaine intake over the testing session (number of injections $\times$ dose per injection; Figure 1a, middle panels). An upward vertical shift in the selfadministration dose-response curve is considered to reflect a transition to a more addicted state, including an increased motivation for drug in animal models (Ahmed and Koob, 1998; Koob et al, 1989; Paterson and Markou, 2003; Richardson and Roberts, 1996). Therefore, these data suggest that TSA infusions may facilitate this transition. Neither of these changes was observed when TSA was infused into the core of NAc (Figure 1b) or the mPFC (Supplementary Figure S2), indicating a region-specific interaction in the mesolimbic system.

To confirm that treatment with TSA results in a stronger motivation for cocaine reinforcement, we studied this effect on cocaine self-administration under a progressive-ratio schedule. During progressive-ratio testing, each cocaine injection requires a progressively greater number of LP responses, and the highest ratio of LPs per cocaine injection performed before the animal quit self-administration altogether reflects the incentive strength of cocaine (Graham et al, 2007). The final ratio of responses successfully completed is defined as the 'break point'. After a stable break point baseline had been established on the progressive-ratio schedule at $750 \mu \mathrm{g} / \mathrm{kg} /$ injection, TSA or vehicle was administered by intra-NAc-shell infusions for 5 days. The rats were subsequently allowed to self-administer cocaine at 500 and $1000 \mu \mathrm{g} / \mathrm{kg} /$ injection under a progressive-ratio schedule, and the same daily intracerebral infusions were administered before each session. As shown in Figure 1c, the control animals receiving vehicle infusions showed a slight extinction-like responding (Richardson and Roberts, 1996) during training for 5 consecutive days $(750 \mu \mathrm{g} / \mathrm{kg} / \mathrm{injection})$, and worked harder for the higher injection dose of cocaine (1000 vs $500 \mu \mathrm{g} / \mathrm{kg}$ ), indicating that the higher dose of cocaine was more reinforcing. In contrast, compared with vehicle-infused control, intraNAc-shell TSA infusions led to a gradually increasing effort to obtain cocaine, achieving higher response/injection ratios at $750 \mu \mathrm{g} / \mathrm{kg} /$ injection (treatment by test day interaction, $F_{4,90}=7.126, P<0.001$; Figure $1 \mathrm{c}$, left panel). On the fifth test day, treatment with TSA increased the break point to 22.8 self-injections compared with a break point of 17.8 in rats treated with vehicle control. The effect of TSA treatment on drug intake is clearer when the data are expressed as the number of LPs the rat performed to obtain the last injection. During the last session, TSA-treated animals performed $479 \pm 65$ LPs on the active lever compared with $207 \pm 29$ LPs by the control animals $\left(\mathrm{F}_{1,17}=12.789, P=0.002\right.$; Figure $1 \mathrm{c}$, left panel $)$. The effect can also be illustrated by expressing the cumulative number of LPs performed by the rats during the entire session $\left(\mathrm{F}_{1,17}=17.831, P<0.001\right.$; data not shown $)$. Similarly, the effect of TSA on the break point was also observed in rats treated at cocaine doses of 500 and $1000 \mu \mathrm{g} / \mathrm{kg} /$ injection (treatment by dose interaction, $F_{1,32}=10.146, P=0.003$; Figure 1c, middle panel). In contrast, neither of these changes was observed when TSA was infused into the NAc core (Figure 1d) or mPFC (Supplementary Figure S2). TSA infused in the core slightly and increased the cumulative LPs $(750 \mu \mathrm{g} / \mathrm{kg} /$ injection $)$ on the fifth test day $\left(\mathrm{F}_{1,14}=5.575\right.$, $P=0.033$; Supplementary Figure S7a left), whereas it had no significant effect on the break point. However, the effect of infusion of TSA into the shell of NAc on the motivation for cocaine was much stronger than the effect of TSA infusion into the core.

The delivery of SAHA, another highly specific inhibitor of class I and class II HDACs, into the NAc shell before the cocaine self-administration test produced similar results (FR5, $\mathrm{F}_{4,96}=2.941, P=0.025$; progressive ratio, $\mathrm{F}_{4,86}=6.245, P<0.001$; Figure 1e). These results showed that intra-NAc-shell infusions of HDAC inhibitors enhance motivation for rat to obtain cocaine, which may be attributable to the potentiation of histone acetylation induced by sustained HDAC inhibition.

\section{Chronic Cocaine Experience Increases Histone Acetylation in the NAc}

We next evaluated whether histone acetylation levels change after acute and chronic administration of cocaine. As shown by western blotting results in Figure $2 a$ and $b$, the acetylation levels of $\mathrm{H} 3$ and $\mathrm{H} 4$ were elevated specifically in the NAc shell $\left(\mathrm{F}_{2,27}=6.327, P=0.006\right.$ and $\mathrm{F}_{2,27}=5.874$, 
a

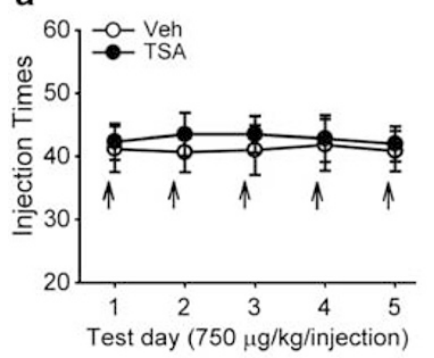

b

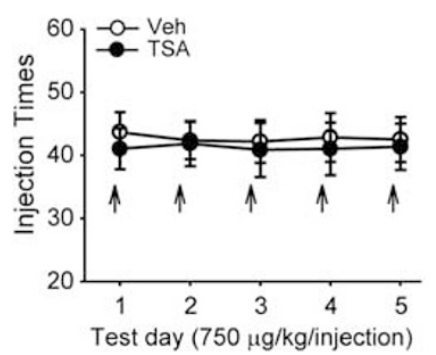

NAc shell

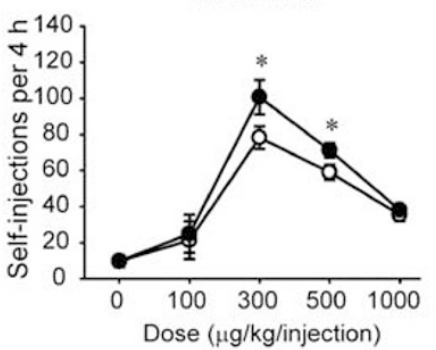

NAc core

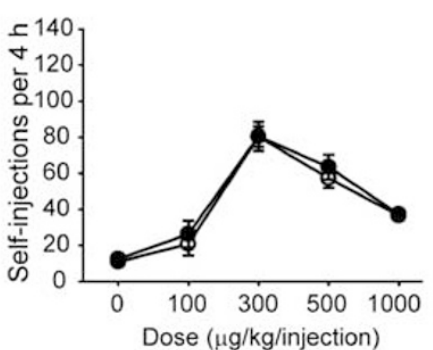

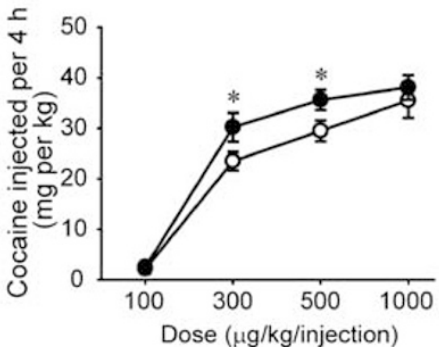

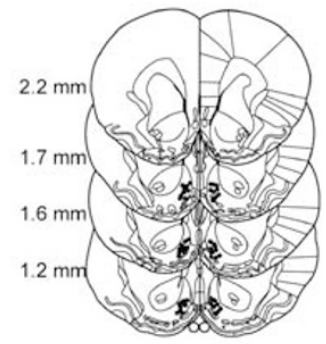

C
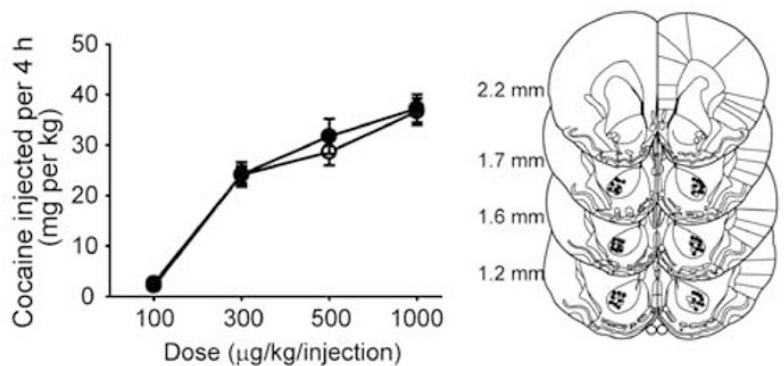

NAc shell
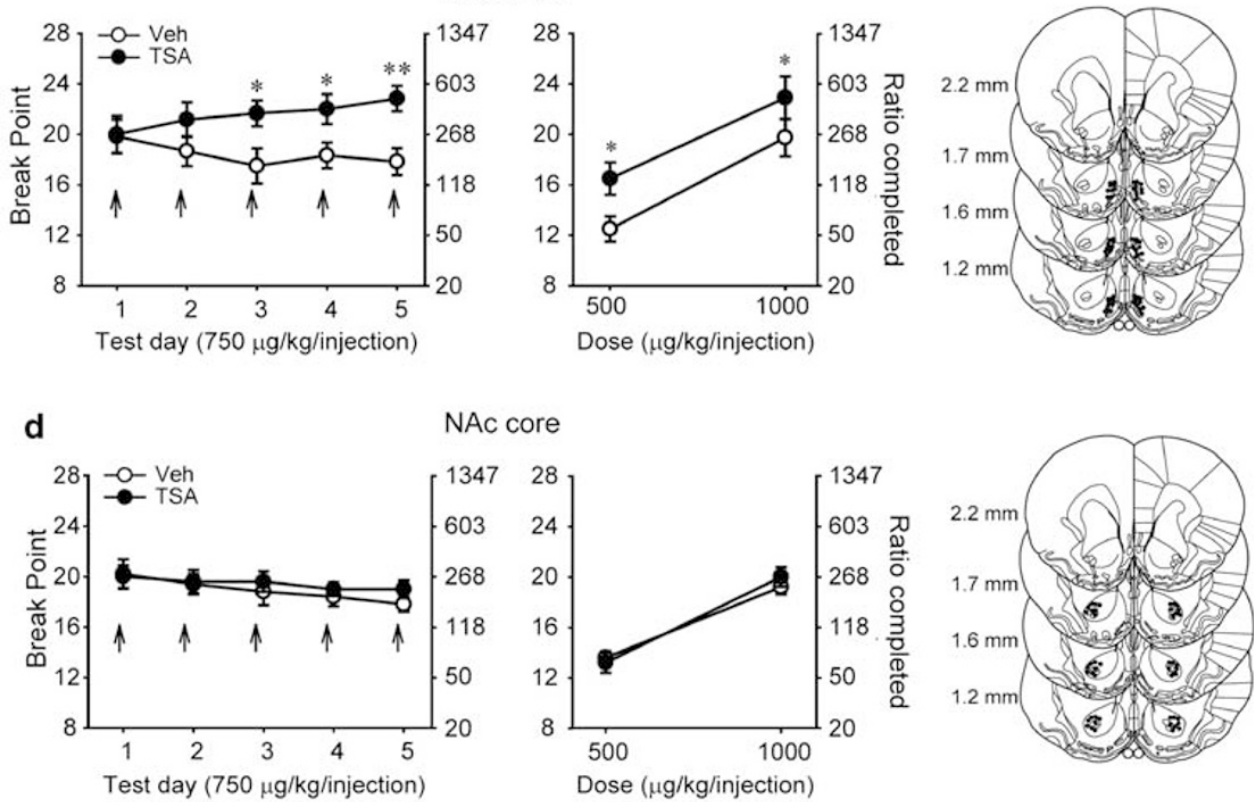

NAc core
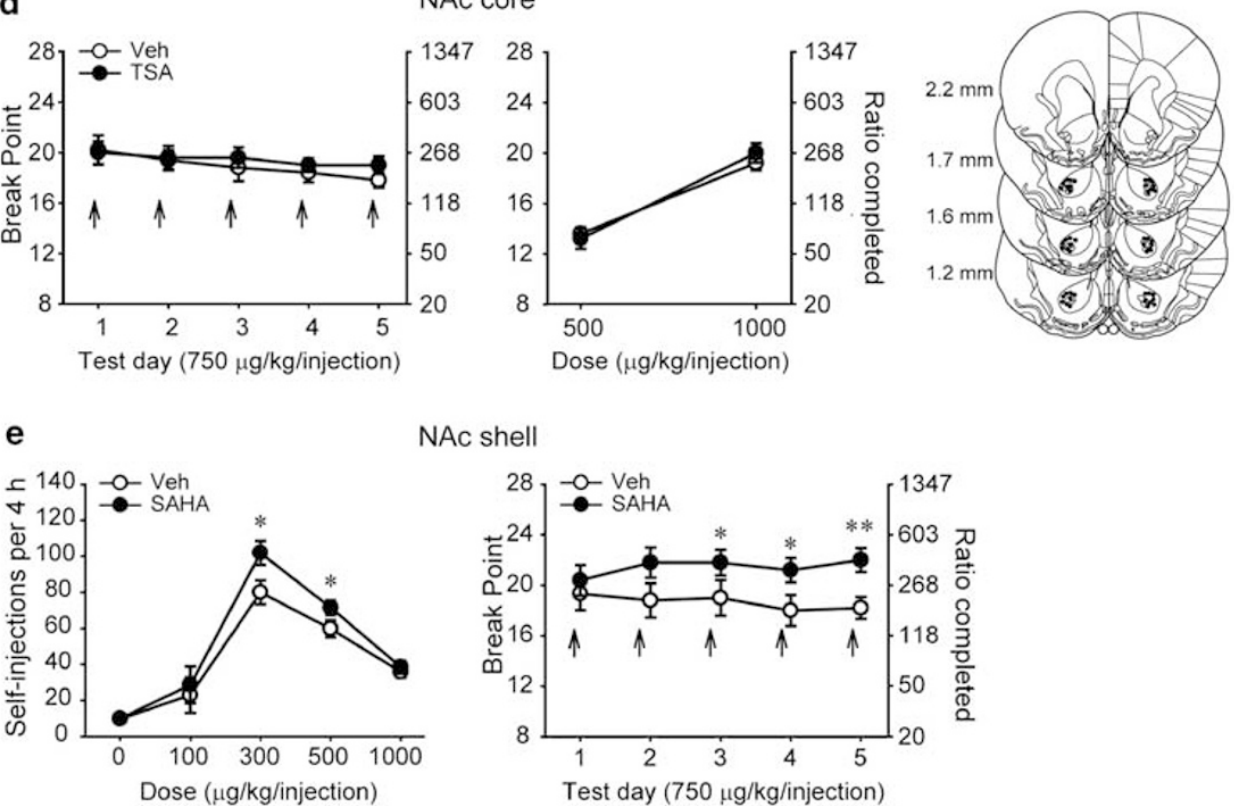

NAc shell

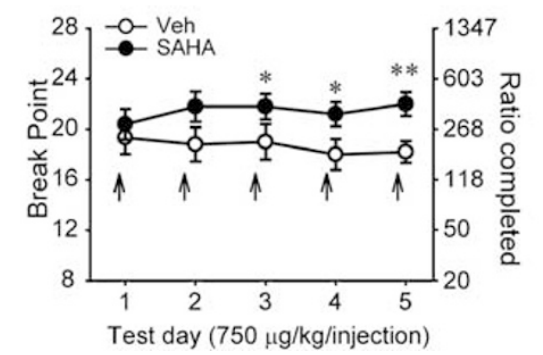

Figure I HDAC inhibitor infusions into the NAc shell increase the motivation for cocaine self-administration. (a, b) Daily infusions of TSA into the shell (a), but not the core (b) of NAc induced an upward shift in dose-response and dose-intake curves under fixed-ratio 5 (FR5) schedule of cocaine selfadministration. (c, d) Daily infusions of TSA into the shell (c), but not the core (d) of NAc increased break point under progressive-ratio schedule. Injection sites in the shell or core are illustrated on the right panel. Daily infusions of SAHA (e) into the shell of NAc increased responding in dose-response curve and break point ( $N=8-12$ per group). Data are expressed as mean $\pm S E M$. $* P<0.05$, $* * P<0.0$ I, compared with vehicle-chronic cocaine control. 
$P=0.008$; Figure $2 \mathrm{a}$ and $\mathrm{b}$, left), but not in the NAc core or the mPFC (data not shown) after chronic intravenous cocaine self-administration experience $(4 \mathrm{~h}$ per day for 18 days). These results were further verified using immunochemistry analysis $\left(\mathrm{AcH} 3, \mathrm{~F}_{2,26}=4.392, P=0.023\right.$; $\mathrm{AcH} 4$, $\mathrm{F}_{2,26}=3.914, P=0.033$; Figure $2 \mathrm{c}$ and $\mathrm{d}$ and Supplementary Figure S3). These sustained histone modifications in the NAc shell could be detected at 3, 12, and even $24 \mathrm{~h}$ after chronic drug use (Supplementary Figure S4a). Cocaine injections delivered to the animals through self-administration (contingent upon LP behavior) or yoked animals (passively administered equal number of injections at the same temporal pattern) resulted in comparable increases in histone acetylation (Figure $2 \mathrm{a}-\mathrm{c}$ ). Moreover, histone acetylation levels in the shell or core of NAc did not changed after acute or chronic sucrose self-administration sessions (data not shown), indicating that the increase in histone acetylation in the NAc was unlikely a result from instrumental learning or generalized exposure to natural rewards. Moreover, histone acetylation levels in the shell or core of NAc or $\mathrm{mPFC}$ in rats receiving acute cocaine through either yoked- or self-administration remained unchanged. Therefore, the elevation of histone acetylation in the NAc shell seems to reflect a generalized pharmacological response to chronic cocaine use.

The effect of HDAC inhibitor infusions on histone acetylation in different encephalic regions was assessed using western analysis after chronic cocaine self-administration. As shown in Figure $2 \mathrm{e}$ and $\mathrm{f}$, the TSA (165 pmol) or SAHA (200 pmol) infusions increased the basal levels of $\mathrm{H} 3$
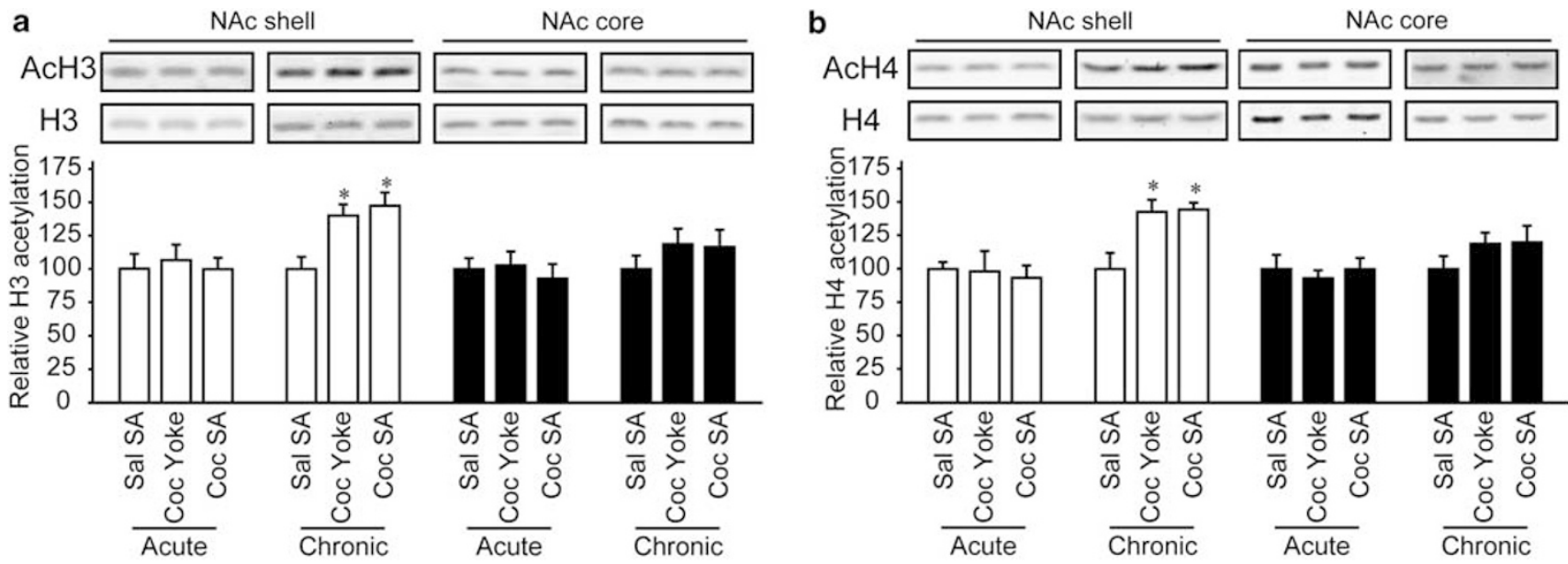

C
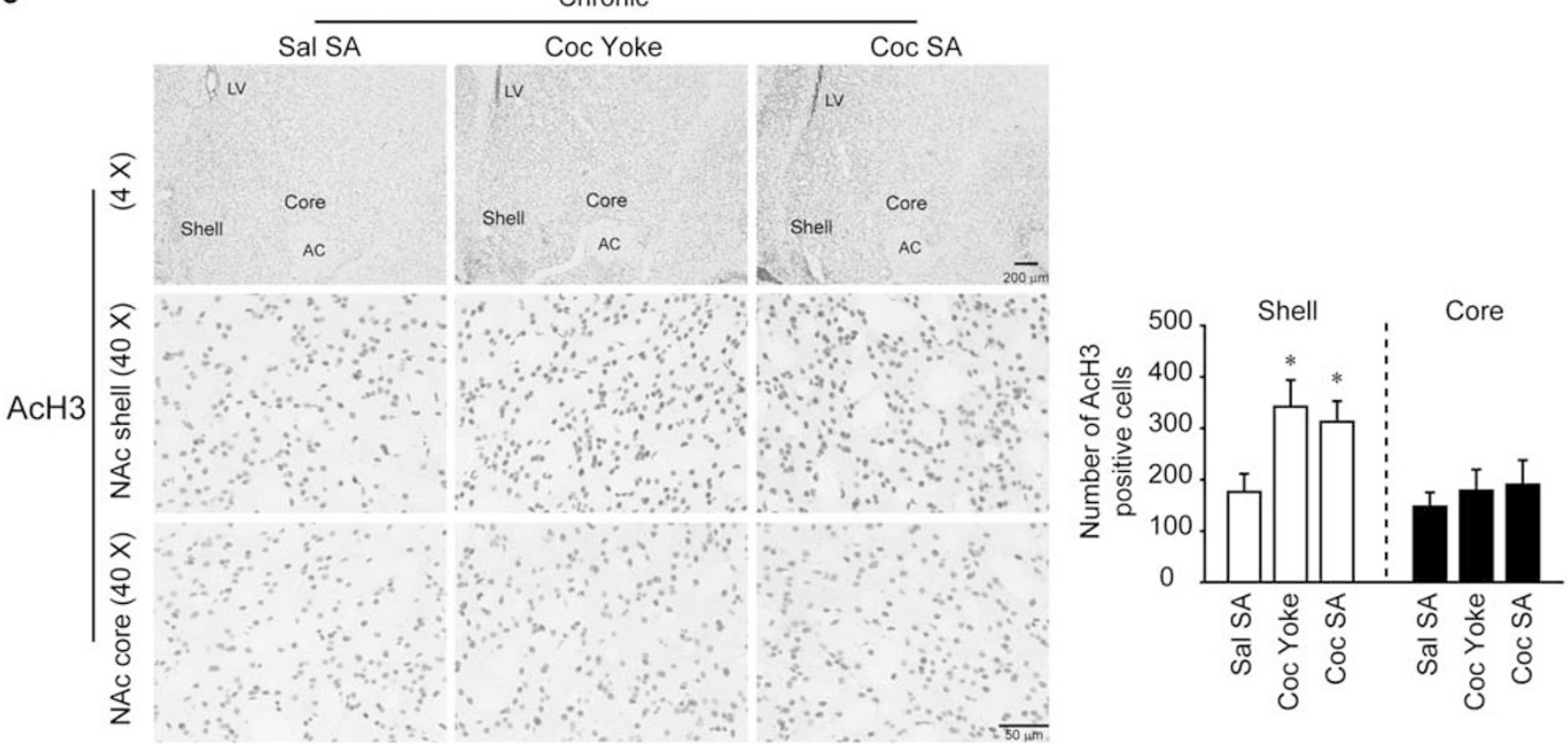

Figure 2 HDAC inhibitor augments histone acetylation elevation induced by chronic cocaine experience in the NAc shell. (a, b) Immunoblots of histone acetylation of $\mathrm{H} 3(\mathrm{AcH} 3)(\mathrm{a})$ and $\mathrm{H} 4(\mathrm{AcH} 4)(\mathrm{b})$ in the shell or core of NAc 30 min after I day (acute) or 18 days (chronic) cocaine yoked (Coc Yoke) or self-administration (Coc SA). (c, d) Immunohistochemistry data of AcH3 (c) and AcH4 (d) in the shell or core of NAc after chronic Coc Yoke or Coc SA. $\mathrm{AC}$, anterior commissure; LV, lateral ventricle. (e, f) $\mathrm{AcH} 3$ (e) and $\mathrm{AcH} 4$ (f) levels after daily HDAC inhibitor infusions in the NAc shell or core. Immunoblot and immunohistochemistry data from cocaine-treated groups $(N=8-12$ per group) are expressed as mean \pm SEM percentage of saline self-administration control ( $N=8-12$ per group). ${ }^{*} P<0.05$, $* * P<0.01$, compared with saline self-administration control or vehicle-chronic saline control; ${ }^{\#} P<0.05$, compared with vehicle-chronic cocaine control. 
d

Chronic

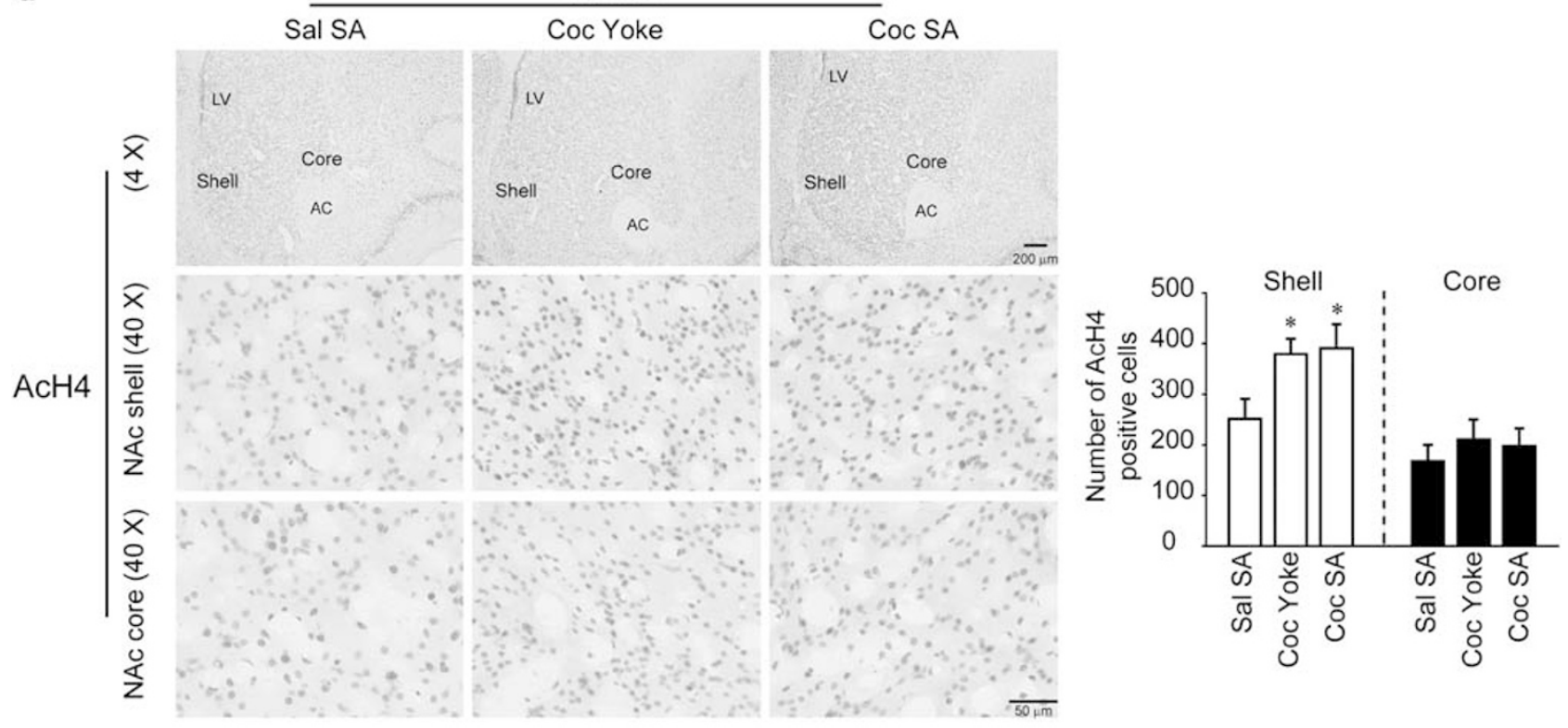

e

NAc shell

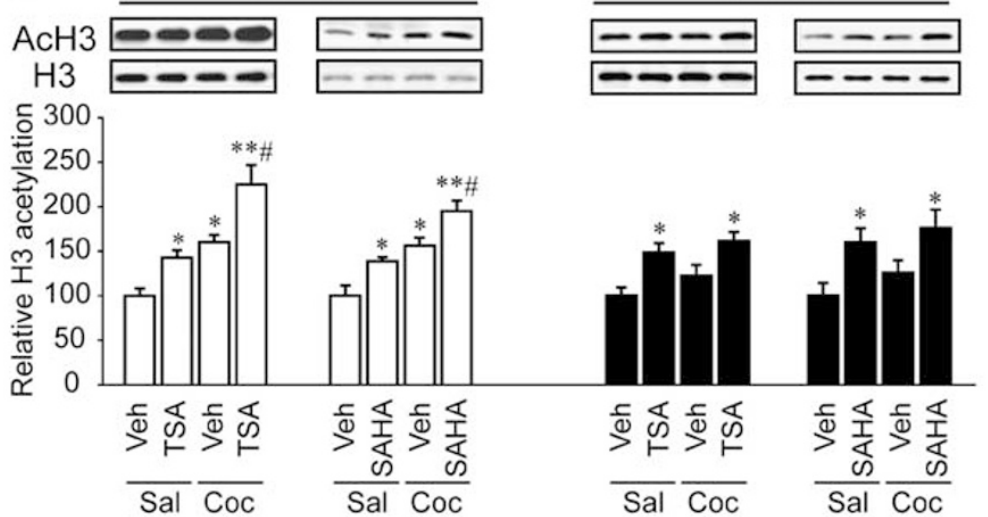

f

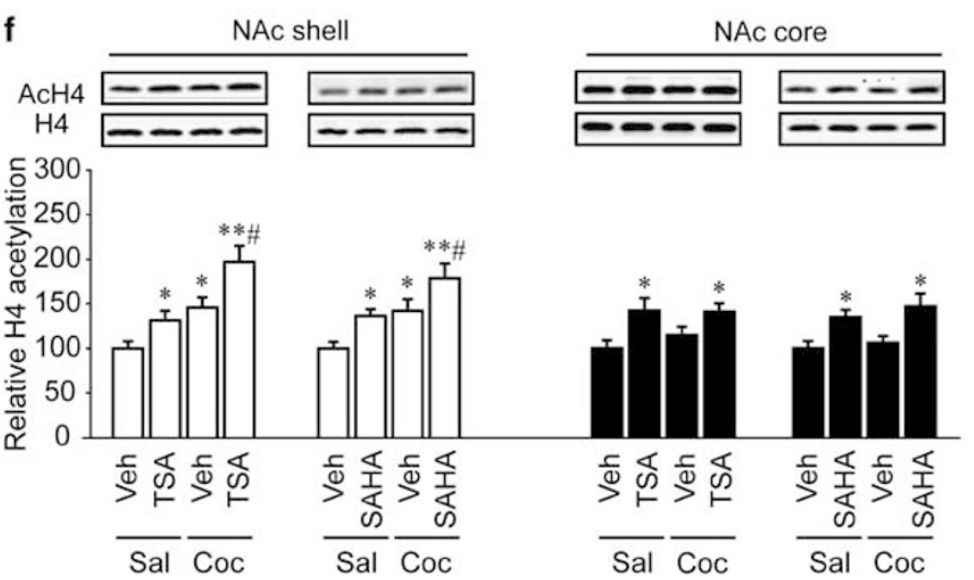

Figure 2 Continued.

and $\mathrm{H} 4$ acetylation in the shell and core of NAc, and in mPFC (data not shown). Chronic cocaine-stimulated increases in histone acetylation in the NAc shell were notably augmented by HDAC inhibitor pretreatment (Figure $2 \mathrm{e}$ and $\mathrm{f}$ ). Moreover, Supplementary Figure S1 shows that HDAC inhibitor administered into the shell of
NAc did not diffuse to the core, or vice versa, and that the infusion of the HDAC inhibitor into the shell or core did not influence histone acetylation in the other site. These data, combined with the observation that the infusion of the HDAC inhibitor into the NAc core had no obvious effect on the dose-response curve or break point, support the notion 
that increased histone acetylation in the NAc shell induced by chronic cocaine self-administration is associated with motivation for drug reinforcement.

\section{Intra-NAc HDAC4 Overexpression Reduces the Motivation for Cocaine Self-Administration}

To gain further insight into the relationship between histone acetylation and the motivation for cocaine selfadministration, we analyzed the effect of neutralizing cocaine-stimulated increase in histone acetylation by overexpressing of HDAC4, a subtype of class II histone deacetylases expressed in the NAc (Renthal et al, 2007). We chose HDAC4 because it is recruited by MEF, SMRT, $B C O R$, and CTBP for transcriptional repression (Bertos et al, 2001). Recombinant adenovirus encoding flag-tagged HDAC4 (AV-HDAC4), truncation mutant of HDAC4 lacking the catalytic domain (AV- $\triangle \mathrm{HDAC} 4)$, or $\beta$-galactosidase (AV-gal) was infused into the NAc shell, NAc core, or mPFC (Figure 3a), and a highly localized overexpression of HDAC4, $\triangle$ HDAC4, or $\beta$-galactosidase was detected in the injected region (Figure $3 \mathrm{~b}$ ). Neurons infected with recombinant adenovirus were localized in the NAc shell (Figure 3b, left panel), NAc core (Figure $3 b$, right panel), or $\mathrm{mPFC}$ without gliosis or scarring (data not shown). As shown in Figure 3c-e and Supplementary Figure S5, the overexpression of full-length HDAC4, but not its truncated form, which lacks deacetylase activity, strongly inhibited the cocaine-induced increase in histone acetylation locally in the NAc shell. The effect of overexpression of HDAC4 in the NAc on self-administration of cocaine was examined 2 weeks after adenoviral infection, during which period the expression of the target protein reached its peak.

The expression of HDAC4 in the NAc did not alter cocaine self-administration at a dose of $750 \mu \mathrm{g} / \mathrm{kg} /$ injection (Figure $3 \mathrm{f}$ and $3 \mathrm{~g}$, left panels). On the FR5 schedule, the dose-response curve shifted downward in the HDAC4overexpressing rats compared with $\beta$-galactosidase (gal) control (treatment by dose interaction, $\mathrm{F}_{8,132}=3.293$, $P=0.002$; Figure 3f, middle panel), and the overall cocaine intake was reduced in these animals across injection doses from 300 to $500 \mu \mathrm{g} / \mathrm{kg} / \mathrm{injection}$ (Figure $3 \mathrm{f}$, right panel). In progressive-ratio testing, intra-NAc-shell HDAC4 overexpression led to a gradually decreased motivation for cocaine, achieving lower response/injection ratios at $750 \mu \mathrm{g} / \mathrm{kg} /$ injection (treatment by test day interaction, $\mathrm{F}_{8,121}=8.149, P<0.001$; Figure $3 \mathrm{~h}$, left panel). On the fifth test day, the overexpression of HDAC4 in the NAc shell reduced the break point to 18.8 self-injections compared with 15.2 in rats treated with gal control. During the last session, HDAC4-overexpressing animals performed $103 \pm 12$ LPs on the active lever, whereas the control group performed $248 \pm 25 \mathrm{LPs}\left(\mathrm{F}_{2,21}=9.124, P=0.007\right.$; Figure $3 \mathrm{~h}$, left panel). This effect can also be expressed as the total number of LPs performed by the rats during an entire session $\left(F_{2,21}=12.938, P=0.002\right.$, data not shown $)$. The results were similar for animals receiving doses of 500 and $1000 \mu \mathrm{g} / \mathrm{kg} /$ injection on the progressive-ratio schedule (treatment by dose interaction, $\mathrm{F}_{2,48}=12.74, P<0.001$; Figure $3 \mathrm{~h}$, right panel). However, overexpression of $\triangle$ HDAC4 had no significant effect on the instrumental responding under the FR5 or progressive-ratio schedule, which confirmed that the effect of HDAC4 expression on the motivation for cocaine self-administration is dependent on its deacetylation activity. Neither of these changes was observed when HDAC4 overexpression was restricted to the NAc core (Figure $3 g$ and i) or mPFC (Supplementary Figure S6). On the fifth test day under progressive-ratio schedule $(750 \mu \mathrm{g} / \mathrm{kg} /$ injection), only the reduction in the cumulative LPs, but not that in the break point, approached statistical significance in animals transfected with HDAC4-recombiniant virus in the NAc core $\left(\mathrm{F}_{2,21}=3.315, P=0.056\right.$; Supplementary Figure S7b). Taken together, these results confirm that the elevation of histone acetylation in the NAc shell is critical for drug motivation.

To analyze whether the response to natural rewards is also regulated by histone acetylation, rats were trained to self-administer sucrose pellets on a FR5 or progressive-ratio schedule, and the effects of HDAC inhibitor treatment and HDAC4 overexpression in the NAc shell were tested using procedures similar to those for cocaine self-administration. As shown in Supplementary Figure S7c-f, HDAC inhibition and HDAC4 overexpression had no effect on the latency of sucrose pellet self-administration or the break point on the progressive-ratio schedule. These data indicate that the altered response to cocaine induced by HDAC inhibition or HDAC4 overexpression involves motivation-related rather than performance-related effects, and suggest that histone acetylation in the NAc shell does not have a prominent role in maintaining natural reward-seeking behaviors.

\section{Motivation for Cocaine is Associated with $\mathrm{H} 3$ Acetylation in the NAc}

To further clarify the different roles of $\mathrm{H} 3$ and $\mathrm{H} 4$ acetylation in the motivation for cocaine reinforcement, the NAc shell was dissected from rats that had acquired a stable break point under the progressive-ratio schedule in chronic cocaine self-administration. The correlation between the break point and histone acetylation was analyzed. The break point correlated positively with the global acetylation level of $\mathrm{H} 3$, but not $\mathrm{H} 4$ (Figure $4 \mathrm{a}$ and b). However, this correlation was not observed in the NAc core (data not shown). These findings support the hypothesis that gene expression regulated by the acetylation of $\mathrm{H} 3$ in the NAc shell may have an important role in the motivation for cocaine.

It has been shown that chronic drug use induces many gene changes in c-Fos, Egr1, AGS3, Creb, Cbp, BDNF, FosB, Cdk5, CaMKII $\alpha, C a M K I I \beta$, GluR2, GluR3, NR2A, NR2B, and Psd95 (Bowers et al, 2004; Bozon et al, 2003; Kumar et al, 2005; Li et al, 2008; McClung and Nestler, 2003; Thiriet et al, 2000; Tsankova et al, 2007). Therefore, the levels of $\mathrm{H} 3$ and $\mathrm{H} 4$ acetylation at the promoters of these genes were analyzed in the shell and core of the NAc using ChIP after chronic saline or cocaine self-administration, or cocaine yoked administration. As shown in Figure $4 \mathrm{c}$ and d, in the NAc shell, chronic cocaine use caused a robust (more than threefold) increase in $\mathrm{H} 3$ acetylation at promoters of $\mathrm{Cbp}$, BDNF-P2, BDNF-P3, FosB, Cdk5, CaMKII $\alpha$, GluR2, NR2A, $N R 2 B$, and Psd95. In contrast, the hyperacetylation of $\mathrm{H} 4$ was only detected at the promoters of Egrl and Psd95. In the NAc core, a slight (approximately twofold) increase in $\mathrm{H} 3$ acetylation was detected at the BDNF-P2, Fos B, Cdk5, 
GluR2, NR2A, NR2B, and Psd95 promoters (Supplementary Table S1). Similar upregulation of $\mathrm{H} 4$ acetylation was observed at the Egrl and Psd95 promoters (Supplementary
Table S2). These data are consistent with the correlation analysis results and indicate that chronic cocaine-induced gene transcriptional activation occurs primarily in the NAc a
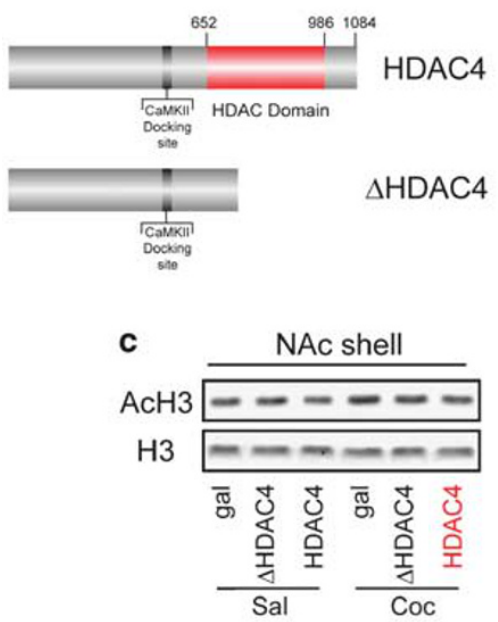

b NAc shell Flag
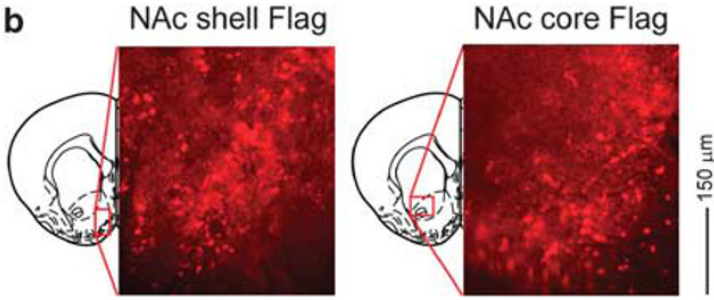

d

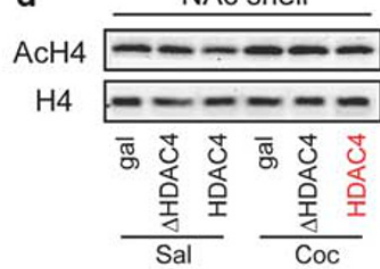

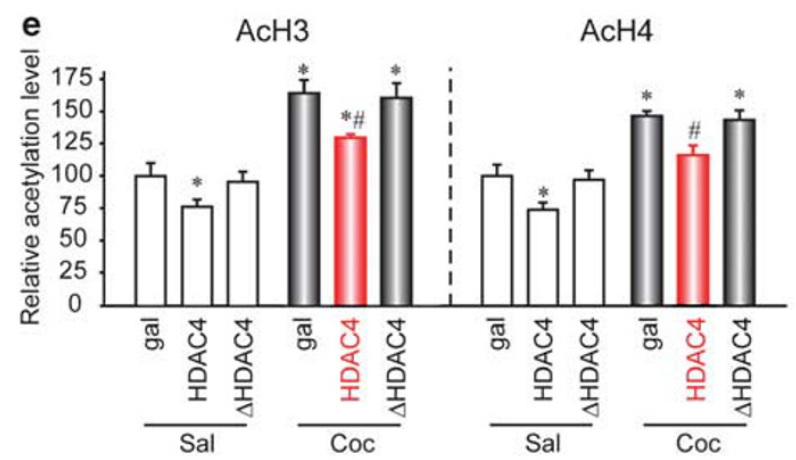

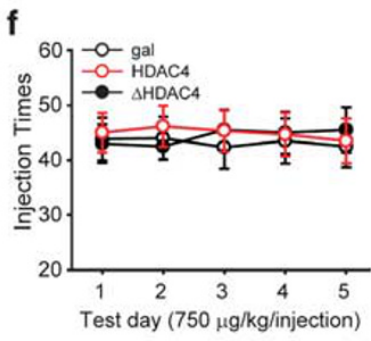

g

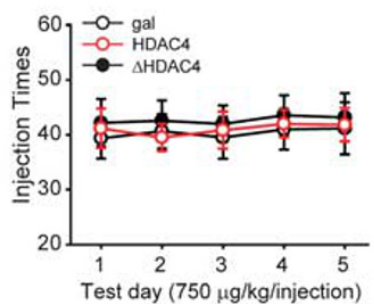

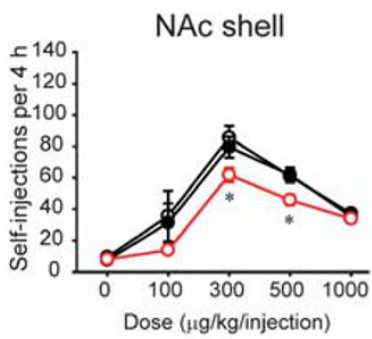

NAc core

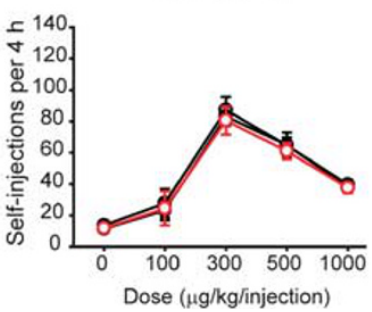

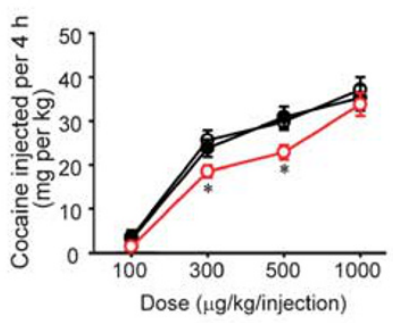

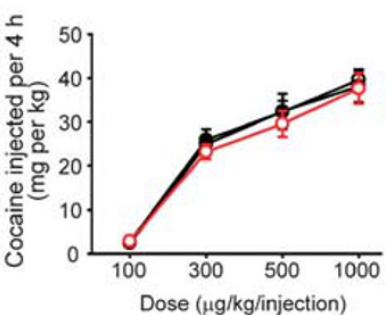

Figure 3 HDAC4 overexpression in the NAc shell downregulates histone acetylation elevation and reduces the motivation for cocaine selfadministration. (a) HDAC4 domain structure, depicting the CaMKII docking site and the catalytic HDAC domain. The HDAC4 truncation ( $\triangle H D A C$ ) without the catalytic HDAC domain used for the behavioral experiments is also shown. (b) Representative staining of AV-HDAC4 in the NAc shell (left) and core (right). Neurons infected with HDAC4 were labeled using Flag immunofluorescence. (c-e) Immunoblots of $\mathrm{AcH} 3$ (c) and $\mathrm{AcH} 4$ (d) in the NAc shell of rats that underwent HDAC4 overexpression. Densitometric quantification of immunoblot in $\mathrm{c}, \mathrm{d}$ (e) of $\mathrm{NAc}$ shell $(\mathrm{N}=8-12$ per group). Data are presented as mean $\pm S E M$. ${ }^{*} P<0.05$, compared with gal-chronic saline control, ${ }^{\#} P<0.05$, compared with gal-chronic cocaine control. (f-i) HDAC4 overexpression in the NAc shell induced a downward shift in dose-response, dose-intake curves $(f)$ and decreased break point (h), but not in the NAc core (g, i). $N=8-12$ per group. Data are expressed as mean \pm SEM. $* P<0.05$, ** $P<0.01$, compared with gal-chronic cocaine control. 


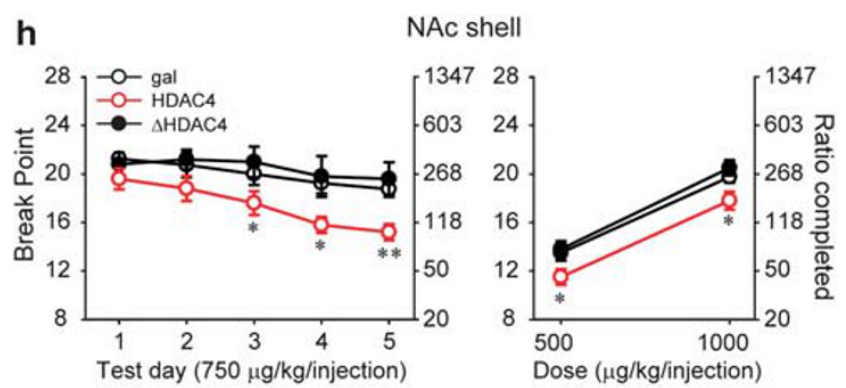

i NAc core

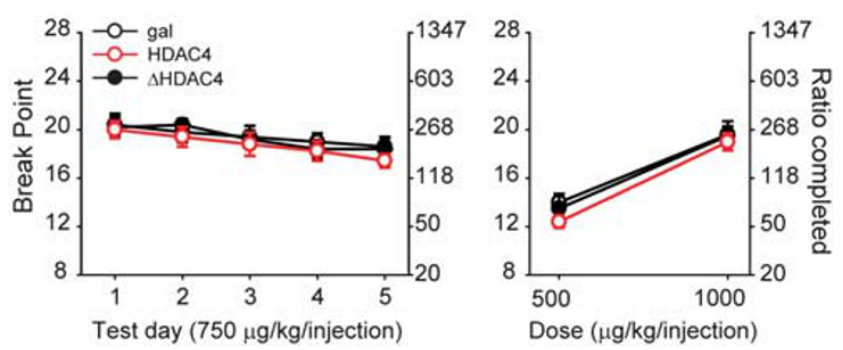

Figure 3 Continued.

shell and is predominantly modulated by the acetylation of $\mathrm{H} 3$.

To analyze the association between the motivation for cocaine and the gene transcriptional activation modulated by $\mathrm{H} 3$ acetylation, the effects of HDAC inhibitor infusions and overexpression of HDAC4 on chronic cocaine-induced histone acetylation at these promoters were further examined using ChIP assays. Daily intra-NAc-shell TSA infusions strongly augmented the increase in chronic cocaine-induced $\mathrm{H} 3$ acetylation at the promoters of $C b p$, BDNF-P2, BDNF-P3, FosB, Cdk5, CaMKII $\alpha$, GluR2, NR2A, and $N R 2 B$ (1.8- to 4.2-fold upregulation; Figure 4e), accompanied by an increase in the motivation for cocaine (Figure 1a and c). The overexpression of HDAC4, but not $\triangle$ HDAC4, in the NAc shell significantly inhibited the chronic cocaine-stimulated elevation of $\mathrm{H} 3$ acetylation at these gene promoters (1.2- to 3.0-fold downregulation; Figure 4f), accompanied by a reduction in motivation (Figure $3 \mathrm{f}$ and $\mathrm{h}$ ). However, neither chronic infusions of HDAC inhibitor nor HDAC overexpression affected $\mathrm{H} 3$ acetylation at these gene promoters in the saline selfadministration group (Figure $4 \mathrm{e}$ and $\mathrm{f}$ ). Moreover, only mild changes in $\mathrm{H} 3$ acetylation were detected at the $B D N F$ $P 2, F o s B, C d k 5, N R 2 A$, and NR2B promoters in the NAc core (0.8- to 2.0-fold upregulation and 0.5 - to 1.2-fold downregulation; Supplementary Figure $\mathrm{S} 8 \mathrm{a}$ and $8 \mathrm{~b}$ ). No significant change in histone acetylation in the mPFC was induced under similar treatment regimens (Supplementary Figure S8c and $8 \mathrm{~d}$ ). These results suggest that drug-induced gene transcriptional activation in the NAc shell, modulated by $\mathrm{H} 3$ acetylation, is a potential mechanism underlying the motivation for cocaine.

\section{Knockdown Expression of CaMKII $\alpha$ in the NAc Decreases the Motivation for Cocaine Self-Administration}

Recently, Anderson et al (2008) showed that CaMKII may be an essential link between the dopamine and glutamate systems of the NAc shell, which are involved in the neuronal plasticity underlying cocaine relapse. However, the relationship between CaMKII and the motivation for cocaine selfadministration is not clear. Therefore, the effect of cocaine administration on the transcript levels of the $\alpha$ and $\beta$ isoforms of CaMKII in the NAc shell were examined using reverse transcription and quantitative PCR. An approximately fourfold upregulation of CaMKII $\alpha$ transcript expression, but no change in CaMKII $\beta$ mRNA level, was observed at $30 \mathrm{~min}$ after the chronic yoked-or self-administration of cocaine (Figure 5a). Furthermore, the mRNA level of $C a M K I I \alpha$, but not $C a M K I I \beta$, correlated positively with the break point (Figure $5 \mathrm{~b}$ and $\mathrm{c}$ ) under progressive-ratio schedule of cocaine self-administration. To confirm the effect of CaMKII $\alpha$ on the motivation for cocaine, we constructed short hairpin RNA (shRNA) expression plasmids $\alpha$ shRNA and $\beta$ shRNA, which specifically and effectively knocked down $>70 \%$ of CaMKII $\alpha$ and CaMKII $\beta$ proteins, respectively (Figure $5 \mathrm{~d}$ ). To locally knockdown the expression of CaMKII $\alpha$ and $C a M K I I \beta$, animals received bilateral NAc shell infusions of recombinant lentivirus encoding CaMKII $\alpha$ shRNA (Lenti- $\alpha$ shRNA), CaMKII $\beta$ shRNA (Lenti- $\beta$ shRNA), or green fluorescent protein (Lenti-GFP). Lentivirus expression reached its peak after seven daily training sessions. As shown in Figure $5 \mathrm{e}-\mathrm{g}$, CaMKII $\alpha$ and CaMKII $\beta$ expression in the NAc shell of animals locally infected with lentivirus encoding the corresponding shRNA was reduced by approximately 39 and $50 \%$, respectively, compared with that in the LentiGFP-transfected control (Figure $5 \mathrm{f}$ and $\mathrm{g}$ ). However, the localized knockdown of CaMKII $\alpha$ or CaMKII $\beta$ expression in the NAc shell did not affect cocaine self-administration at $750 \mu \mathrm{g} / \mathrm{kg} /$ injection (data not shown).

The effects of the different isoforms of CaMKII on the motivation for cocaine self-administration on behavior were analyzed under progressive-ratio schedule. As shown in Figure $5 \mathrm{~h}$, intra-NAc-shell Lenti- $\alpha$ shRNA infusions led to a gradual reduction in the motivation for cocaine and the effect was statistically significant on the fifth test day at a dose of $750 \mu \mathrm{g} / \mathrm{kg} /$ injection compared with the effect of the Lenti-GFP control $\left(\mathrm{F}_{2,26}=5.084, P=0.014\right.$, Figure $5 \mathrm{~h}$, left panel). A similar effect was observed at doses of 500 and $1000 \mu \mathrm{g} / \mathrm{kg} /$ injection on progressive-ratio schedule $\left(\mathrm{F}_{2,43}=4.342, P=0.019\right.$; Figure $5 \mathrm{~h}$, right panel $)$. Interestingly, the knockdown of CaMKII $\beta$ expression by Lenti$\beta$ shRNA in the NAc shell had no significant effect under the same conditions, indicating a specific interaction between the motivation for cocaine and the different isoforms of CaMKII. However, the knockdown of CaMKII $\alpha$ expression in the NAc shell had no significant effect on motivation for sucrose (data not shown). Collectively, these data indicate that CaMKII $\alpha$ expression in the NAc shell, regulated by the cocaine-induced elevation of $\mathrm{H} 3$ acetylation, is involved in the motivation for cocaine self-administration.

\section{DISCUSSION}

Drug-induced changes in gene expression in key brain reward regions are thought to contribute to long-lasting behavioral abnormalities and neuroadaptation (Hyman et al, 2006; Koob and Kreek, 2007; Kumar et al, 2005). 

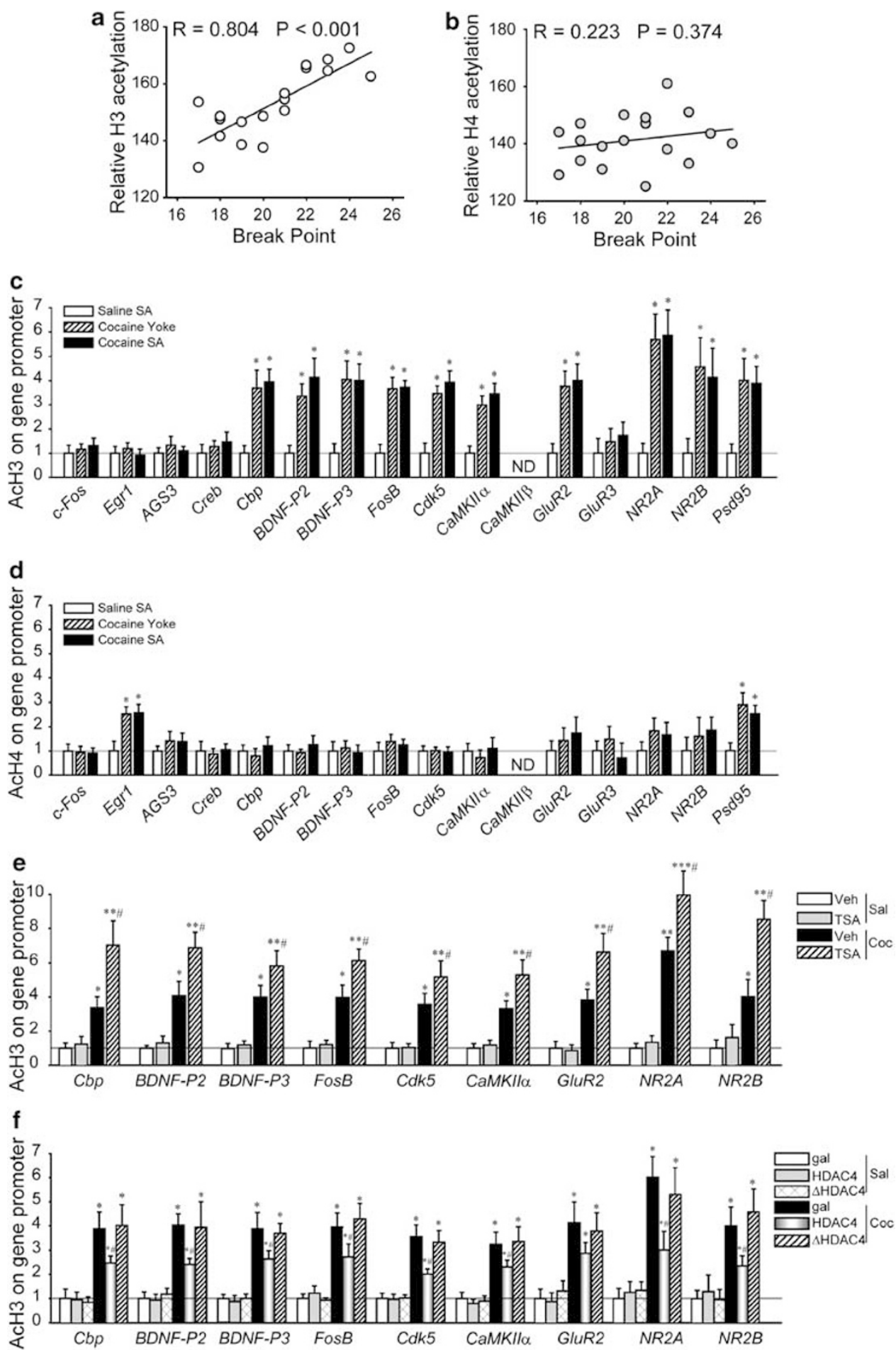

Figure 4 Motivation for cocaine is associated with $\mathrm{H} 3$ acetylation in the NAc shell. $(\mathrm{a}, \mathrm{b})$ The break point was positively correlated with global level of $\mathrm{AcH} 3$ (a), but not $\mathrm{AcH} 4$ (b) in the NAc shell. Diagonal solid lines indicate linear regression fit of data points $(N=18)$. (c, d) Changes of histone acetylation in specific gene promoter regions in the NAc shell under progressive-ratio schedule $(N=6-8$ per group). Data are presented as mean $\pm S E M$. $* P<0.05$, compared with saline self-administration control, ND, acetylation not detected. (e, $f$ ) The effect of HDAC inhibitor (e) or HDAC4 overexpression ( $f$ ) on $\mathrm{AcH} 3$ at the indicated gene promoters in the NAc shell under progressive-ratio schedule $(\mathrm{N}=8-10$ per group). Data are presented as mean $\pm \mathrm{SEM}$. ${ }^{*} P<0.05$, ${ }^{*} * P<0.01$, ${ }^{*} * * P<0.00 I$, compared with vehicle- or gal-chronic saline control, ${ }^{\#} P<0.05$, compared with vehicle- or gal-chronic cocaine control.

Genome-wide mRNA analysis has identified many potential gene targets for drugs of abuse in distinct brain reward regions (Freeman et al, 2001; McClung and Nestler, 2003;
McClung et al, 2005; Winstanley et al, 2007; Yao et al, 2004). Therefore, it is of great interest to identify the underlying mechanisms by which chronic cocaine experience promote 

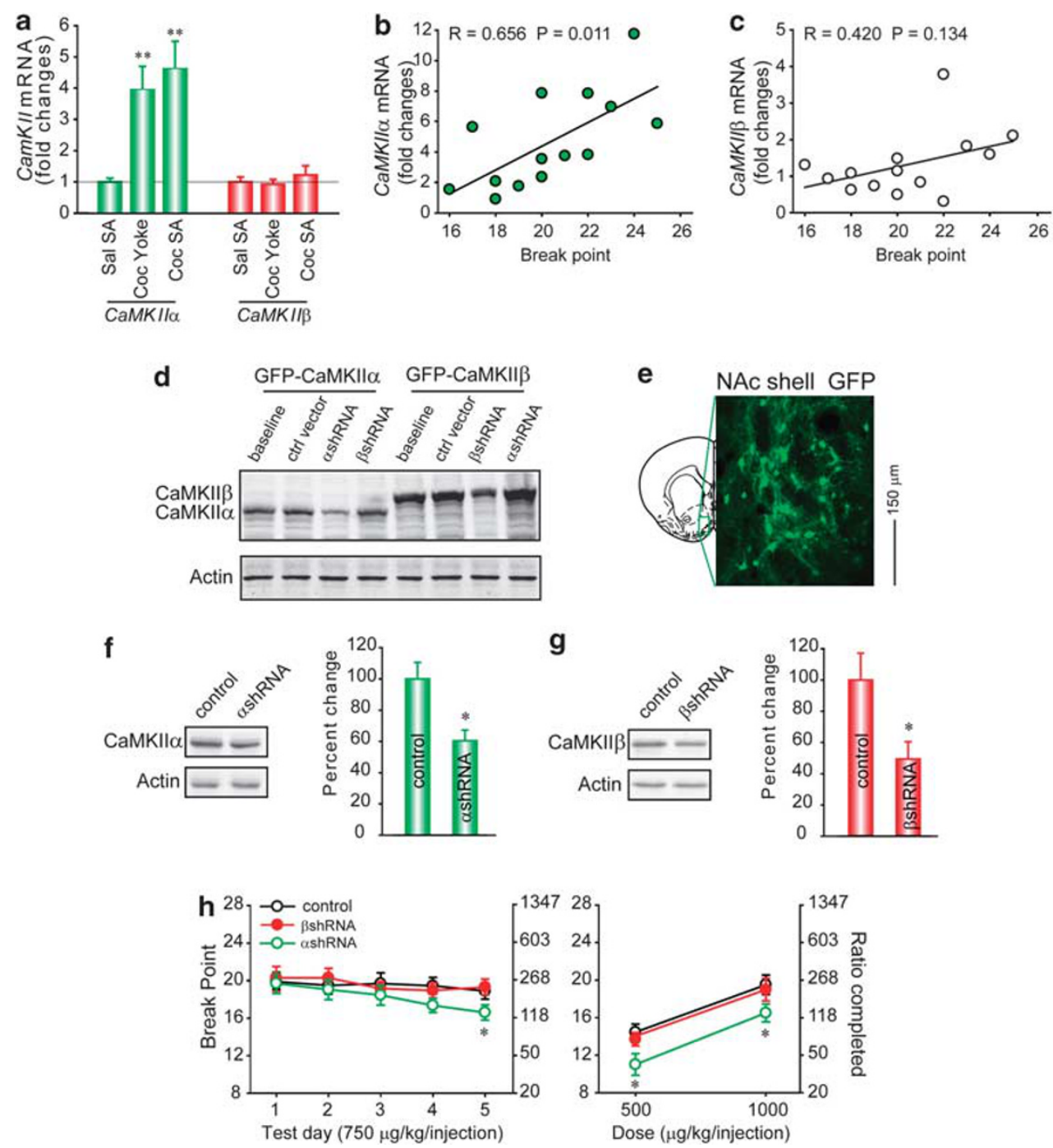

Figure 5 Localized CaMKIl $\alpha$ knockdown in the NAc shell decreases the motivation for cocaine. (a) CaMKIl $\alpha$ but not CaMKII $\beta$ mRNA levels were increased in the NAc shell 30 min after chronic cocaine yoked or self-administration ( $N=8-12$ per group). Data are expressed as mean $\pm S E M$. *** $<0.01$, compared with chronic saline self-administration control. (b, c) The break point was correlated with level of CaMKIl $\alpha$ mRNA (b), but not CaMKII $\beta$ mRNA (c) in the NAc shell. Diagonal solid lines indicate linear regression fit of data points $(N=14)$. (d) GFP-tagged CaMKIl $\alpha$ or CaMKII $\beta$ were cotransfected into HEK293T cells with or without plasmid encodes shRNA for CaMKIl $\alpha$ ( $\alpha$ shRNA) or CaMKII $\beta$ ( $\beta$ shRNA) expression and the cell lysate was immunoblotted with anti-GFP antibody. pBS-hU6 (vector) was used as a control. (e) Localized Lenti-GFP expression in the NAc shell. (f, g) Immunoblot from the NAc shell infected with Lenti- $\alpha$ shRNA or Lenti- $\beta$ shRNA showed a reduction in protein level of CaMKIll $\alpha(f)$ or CaMKII $\beta$ ( $g$ ), compared with Lenti-GFP control ( $N=8-10$ / group). Data are expressed as mean \pm SEM. $* P<0.05$, compared with Lenti-GFP control. ( $h$ ) Intra-NAc-shell Lenti- $\alpha$ shRNA infusions decreased the motivation for cocaine ( $N=8-12$ per group). Data are expressed as mean \pm SEM. $* P<0.05$, compared with Lenti-GFP control.

sustained changes in gene expression. Recent evidence has prompted the notion that epigenetic mechanisms exert lasting effects on gene expression through the regulation of chromatin structure. Increasing evidence indicates that hyperacetylation in promoter regions is strongly associated with gene transcriptional activation, whereas hypoacetylation correlates with reduced gene expression (Kurdistani et al, 2004; Pokholok et al, 2005). This association also exists in the brain in vivo in response to drug abuse. For example, chronic exposure to cocaine is known to activate a set of genes (eg, Cdk5 and BDNF) in the NAc, and the expression of some of these genes remains elevated for days to weeks (Bowers et al, 2004; Grimm et al, 2003; ; Yao et al, 2004). Consistent with these changes in gene expression, increased $\mathrm{H} 3$ acetylation at the gene promoters of $C d k 5$ and
$B D N F$, which last at least a week, has also been observed after chronic cocaine administration (Kumar et al, 2005). Genome-wide ChIP-chip analysis has shown that a large number of genes are $\mathrm{H} 3$ acetylated in the NAc in response to chronic cocaine exposure, whereas a significant set of previously unrecognized genes are hyperacetylated only on H4 (Renthal et al, 2009; Renthal and Nestler, 2008). In our experiment, the shell and core of the NAc were examined as two distinct regions. Our data show that chronic self- and experimenter-administered cocaine induced long-term increases in global $\mathrm{H} 3$ and $\mathrm{H} 4$ acetylation in the NAc shell, but showed only an increasing trend in the NAc core. This indicates that chronic cocaine may activate more genes and induce stronger transcriptional activation in the shell of the NAc than in the core. 
The present hypothesis is that an escalation in cocaine intake predicts an increase in the hedonic set-point accompanied by an increased motivation for the drug, rather than the development of tolerance, which is generally indicated by a rightward shift in the curve (Ahmed et al, 2000; Emmett-Oglesby et al, 1993; Li et al, 1994). In this context, escalating vertical shifts in the dose-response curve may reflect changes in the self-injection of the drug reward with an increase in the motivation to take the drug (increased peak or maximum rate of behavior). In contrast, mere tolerance to the pharmacological effects of the drug would only shift the curve to the right, without changing the maximum rate of behavior (Ahmed and Koob, 2004). This theory is consistent with our current results, which showed that daily HDAC inhibitor infusions into the NAc shell led to enduring increased responding in the dose-response curve on a fixed-ratio schedule, with higher peak selfadministration rates or break point on a progressive-ratio schedule of cocaine self-administration.

To analyze the role of histone acetylation in the NAc shell in the motivation for cocaine, two specific HDAC inhibitors, TSA and SAHA, were used to augment the increase in histone acetylation. These treatments enhanced the motivation for cocaine, as reflected by the upward shift in doseresponse curve and the increase of break point. The findings were similar when a third HDAC inhibitor, valproic acid (50 nmol per side), was infused into the NAc shell (data not shown). The neutralization of these changes by the intraNAc-shell adenovirus-mediated overexpression of HDAC reduced the motivation for cocaine. Taken together, these effects suggest that the elevation of histone acetylation in the NAc shell during chronic cocaine use is critical in regulating the motivation for cocaine.

Two key properties of drug addiction are increased intake over time' and 'increased time and energy devoted to acquiring the drug'. The motivational property for drug reinforcement can be analyzed using a progressive-ratio schedule, which has been shown to be very useful in evaluating not only the reinforcing efficacy of the drug of abuse, but also the effect of a variety of pretreatments (Richardson and Roberts, 1996). Roberts and his colleagues have shown that the break point, which is derived from the progressive-ratio schedule, reflects the maximal effort (the increased time and energy devoted to acquire cocaine; Oleson and Roberts, 2009) made to receive a drug infusion and is sensitive to pharmacological challenge (Richardson and Roberts, 1996). Our present data show that chronic cocaine use induced an increase in histone acetylation of $\sim 50 \%$, and augmenting this increase in histone acetylation with HDAC inhibitors resulted in an increase in the break point of $20-27 \%$. Although these changes are moderate, they reflect physiologically significant biochemical and behavioral alterations during the development of addiction. These results imply that the chronic cocaine-induced hyperacetylation of histone is associated with the enhanced motivation for the drugs.

A series of studies have identified an interesting phenomenon, 'incubation', which is a time-dependent increase in cocaine seeking induced by cocaine abstinence (Grimm et al, 2001; Lu et al, 2005). Persistent changes in gene expression, including that of immediate early genes, have been observed during incubation. Freeman et al (2008) reported the altered expression of EGR1 and NPY after the cessation of drug administration, which was regulated by $\mathrm{H} 3$ acetylation. Recently, Romieu et al (2008) found that the daily systemic administration of TSA during the initial phase of cocaine self-administration reduced the instrumental responding including break point, which may have important implications for the effects of epigenetic mechanisms in the early stage of addiction (acquisition of cocaine self-administration). In our experiments, we analyzed the role of histone acetylation in specific brain regions during the chronic phase of cocaine self-administration (long-term reinforcement of cocaine self-administration for more than 30 days). Our data show that chronic drug experience induce H3-acetylation-regulated gene transcriptional activation, which is a critical molecular mechanism underlying the increased motivation for drug reinforcement. Although different neurobiological mechanisms may be involved, gene transcriptional activation in the mesolimbic system, modulated by histone modification, underlies the development of drug addiction throughout its different phases, including the initial, reinforcement, and incubation stages.

A ChIP assay was performed to analyze the gene transcriptional activation modulated by histone acetylation after chronic cocaine use, especially chronic self-administration. We found that chronic cocaine use caused a robust induction of the acetylation of $\mathrm{H} 3$, but not $\mathrm{H} 4$, at promoters of Cbp, BDNF-P2, BDNF-P3, FosB, Cdk5, CaMKII $\alpha$, GluR2, $N R 2 A$, and $N R 2 B$ in the NAc shell. Furthermore, the fact that the inhibition or expression of HDAC induced changes in the motivation for cocaine self-administration is consistent with changes in histone acetylation at these gene promoters. These results strongly suggest that gene transcriptional activation induced by $\mathrm{H} 3$ acetylation in the NAc shell may have an important role in modulating the motivation for cocaine reinforcement. Recent studies have shown that although the hyperacetylation of $\mathrm{H} 4$ was detected at the promoters of a significant number of genes after chronic drug treatment, a larger number of genes are regulated by $\mathrm{H} 3$ acetylation rather than by $\mathrm{H} 4$ acetylation (783 vs 471) (Renthal et al, 2009; Renthal and Nestler, 2008) It will be interesting to analyze the molecular mechanisms by which chronic cocaine use preferentially induces the hyperacetylation of $\mathrm{H} 3$ at gene promoters, and to extend our study of the role of $\mathrm{H} 4$ acetylation in drug addiction.

CaMKII, a member of the $\mathrm{Ca}^{2+} /$ calmodulin-dependent protein kinase family, is a ubiquitous serine/threonine protein kinase consisting of four isozymes $(\alpha, \beta, \gamma$, and $\delta)$. It is highly enriched in brain tissue. The brain-specific $\alpha$ and $\beta$ isoforms constitute up to $2 \%$ of the total protein in the hippocampus of rodents and up to $1 \%$ of the total protein in the forebrain itself, whereas the other two isozymes $(\gamma$ and $\delta$ ) are present at $\sim 0.02 \%$ of the level of the brain-specific forms (Erondu and Kennedy, 1985; Tobimatsu and Fujisawa, 1989). Neuronal CaMKII regulates important neuronal functions, including neurotransmitter synthesis and release, the modulation of ion channel activity, synaptic plasticity, and gene expression (Mima et al, 2001). A previous study showed that CaMKII phosphorylates NR2B and Psd95 to regulate signal transduction downstream from the $N$-methyl-D-aspartic acid (NMDA) receptor (Gardoni 
et al, 2006; Liu et al, 2006). Recent work showed that the activation of CaMKII has a key role in the development and maintenance of the addiction state, and that fast and slow positive feedback loops are interlinked through CaMKII underlying drug addiction (Li et al, 2008). Recent work by Wang and colleagues showed that CaMKII $\alpha$ could relieve the D3R-mediated inhibition on sensitized behavior to foster drug-seeking behavior, implicating CaMKII $\alpha$ as an important negative regulator of D3R (Liu et al, 2009). In our experiments, we analyzed the effects of different isoforms of CaMKII on drug reinforcement responses. We found that CaMKII $\alpha$, but not CaMKII $\beta$, was robustly induced by chronic cocaine use and that this correlated with the motivation for cocaine. Furthermore, using the localized knockdown of CaMKII $\alpha$ expression, we found that CaMKII $\alpha$ is required for the maintenance of the motivation. Considering these data collectively, we propose that CaMKII $\alpha$ may be a key molecule regulating the motivation for cocaine, similar to other well-established proteins such as BDNF, FosB, and so on.

\section{ACKNOWLEDGEMENTS}

This research was supported by grants from the Ministry of Science and Technology (2005CB522406, 2009CB522000, and 2009ZX09303-006), National Natural Science Foundation of China (30830042 and 30821002), Shanghai Leading Academic Discipline Project (B119), and Research Fund for the Doctoral Program of Higher Education of China for Youth Scholars (20070246047).

\section{DISCLOSURE}

The authors declare no conflict of interest.

\section{REFERENCES}

Ahmed S, Koob G (2004). Vertical shifts in dose-injection curves reflect reward allostasis, not sensitization. Psychopharmacology 171: 354-355.

Ahmed SH, Koob GF (1998). Transition from moderate to excessive drug intake: change in hedonic set point. Science 282: $298-300$.

Ahmed SH, Walker JR, Koob GF (2000). Persistent increase in the motivation to take heroin in rats with a history of drug escalation. Neuropsychopharmacology 22: 413-421.

Anderson SM, Famous KR, Sadri-Vakili G, Kumaresan V, Schmidt HD, Bass CE et al. (2008). CaMKII: a biochemical bridge linking accumbens dopamine and glutamate systems in cocaine seeking. Nat Neurosci 11: 344-353.

Belin D, Everitt BJ (2008). Cocaine seeking habits depend upon dopamine-dependent serial connectivity linking the ventral with the dorsal striatum. Neuron 57: 432-441.

Bertos NR, Wang AH, Yang XJ (2001). Class II histone deacetylases: structure, function, and regulation. Biochem Cell Biol 79: 243-252.

Bowers MS, McFarland K, Lake RW, Peterson YK, Lapish CC, Gregory ML et al. (2004). Activator of G protein signaling 3: a gatekeeper of cocaine sensitization and drug seeking. Neuron 42: 269-281.

Bozon B, Davis S, Laroche S (2003). A requirement for the immediate early gene zif268 in reconsolidation of recognition memory after retrieval. Neuron 40: 695-701.
Brami-Cherrier K, Valjent E, Herve D, Darragh J, Corvol JC, Pages C et al. (2005). Parsing molecular and behavioral effects of cocaine in mitogen- and stress-activated protein kinase-1deficient mice. J Neurosci 25: 11444-11454.

Chakrabarti SK, James JC, Mirmira RG (2002). Quantitative assessment of gene targeting in vitro and in vivo by the pancreatic transcription factor, Pdx1. Importance of chromatin structure in directing promoter binding. J Biol Chem 277: 13286-13293.

Choi KH, Whisler K, Graham DL, Self DW (2006). Antisenseinduced reduction in nucleus accumbens cyclic AMP response element binding protein attenuates cocaine reinforcement. Neuroscience 137: 373-383.

Colvis CM, Pollock JD, Goodman RH, Impey S, Dunn J, Mandel G et al. (2005). Epigenetic mechanisms and gene networks in the nervous system. J Neurosci 25: 10379-10389.

Courtin C, Crete D, Canestrelli C, Noble F, Marie-Claire C (2006). Regulation of genes involved in dopamine transporter modulation by acute cocaine in rat striatum. Neurosci Lett 398: 235-240.

Di Ciano P, Robbins TW, Everitt BJ (2008). Differential effects of nucleus accumbens core, shell, or dorsal striatal inactivations on the persistence, reacquisition, or reinstatement of responding for a drug-paired conditioned reinforcer. Neuropsychopharmacology 33: $1413-1425$.

Emmett-Oglesby MW, Peltier RL, Depoortere RY, Pickering CL, Hooper ML, Gong YH et al. (1993). Tolerance to selfadministration of cocaine in rats: time course and dose-response determination using a multi-dose method. Drug Alcohol Depend 32: 247-256.

Erondu NE, Kennedy MB (1985). Regional distribution of type II $\mathrm{Ca} 2+$ /calmodulin-dependent protein kinase in rat brain. J Neurosci 5: 3270-3277.

Etchegaray JP, Lee C, Wade PA, Reppert SM (2003). Rhythmic histone acetylation underlies transcription in the mammalian circadian clock. Nature 421: 177-182.

Everitt BJ, Robbins TW (2005). Neural systems of reinforcement for drug addiction: from actions to habits to compulsion. Nat Neurosci 8: 1481-1489.

Freeman WM, Nader MA, Nader SH, Robertson DJ, Gioia L, Mitchell SM et al. (2001). Chronic cocaine-mediated changes in non-human primate nucleus accumbens gene expression. J Neurochem 77: 542-549.

Freeman WM, Patel KM, Brucklacher RM, Lull ME, Erwin M, Morgan D et al. (2008). Persistent alterations in mesolimbic gene expression with abstinence from cocaine self-administration. Neuropsychopharmacology 33: 1807-1817.

Gardoni F, Polli F, Cattabeni F, Di Luca M (2006). Calciumcalmodulin-dependent protein kinase II phosphorylation modulates PSD-95 binding to NMDA receptors. Eur J Neurosci 24: 2694-2704.

Graham DL, Edwards S, Bachtell RK, DiLeone RJ, Rios M, Self DW (2007). Dynamic BDNF activity in nucleus accumbens with cocaine use increases self-administration and relapse. Nat Neurosci 10: 1029-1037.

Grimm JW, Hope BT, Wise RA, Shaham Y (2001). Neuroadaptation. Incubation of cocaine craving after withdrawal. Nature 412: 141-142.

Grimm JW, Lu L, Hayashi T, Hope BT, Su TP, Shaham Y (2003). Time-dependent increases in brain-derived neurotrophic factor protein levels within the mesolimbic dopamine system after withdrawal from cocaine: implications for incubation of cocaine craving. J Neurosci 23: 742-747.

Guan JS, Haggarty SJ, Giacometti E, Dannenberg JH, Joseph N, Gao $J$ et al. (2009). HDAC2 negatively regulates memory formation and synaptic plasticity. Nature 459: 55-60.

Hockly E, Richon VM, Woodman B, Smith DL, Zhou X, Rosa E et al. (2003). Suberoylanilide hydroxamic acid, a histone deacetylase inhibitor, ameliorates motor deficits in a mouse 
model of Huntington's disease. Proc Natl Acad Sci USA 100: 2041-2046.

Hoshino M, Tagawa K, Okuda T, Murata M, Oyanagi K, Arai N et al. (2003). Histone deacetylase activity is retained in primary neurons expressing mutant huntingtin protein. J Neurochem 87: 257-267.

Hsieh J, Gage FH (2004). Epigenetic control of neural stem cell fate. Curr Opin Genet Dev 14: 461-469.

Huang Y, Doherty JJ, Dingledine R (2002). Altered histone acetylation at glutamate receptor 2 and brain-derived neurotrophic factor genes is an early event triggered by status epilepticus. J Neurosci 22: 8422-8428.

Hyman SE, Malenka RC, Nestler EJ (2006). Neural mechanisms of addiction: the role of reward-related learning and memory. Annu Rev Neurosci 29: 565-598.

Ito R, Robbins TW, Everitt BJ (2004). Differential control over cocaine-seeking behavior by nucleus accumbens core and shell. Nat Neurosci 7: 389-397.

Kalivas PW, Volkow N, Seamans J (2005). Unmanageable motivation in addiction: a pathology in prefrontal-accumbens glutamate transmission. Neuron 45: 647-650.

Koob G, Kreek MJ (2007). Stress, dysregulation of drug reward pathways, and the transition to drug dependence. $\mathrm{Am}$ J Psychiatry 164: 1149-1159.

Koob GF, Stinus L, Le Moal M, Bloom FE (1989). Opponent process theory of motivation: neurobiological evidence from studies of opiate dependence. Neurosci Biobehav Rev 13: 135-140.

Kumar A, Choi KH, Renthal W, Tsankova NM, Theobald DE, Truong HT et al. (2005). Chromatin remodeling is a key mechanism underlying cocaine-induced plasticity in striatum. Neuron 48: 303-314.

Kurdistani SK, Tavazoie S, Grunstein M (2004). Mapping global histone acetylation patterns to gene expression. Cell 117: 721-733.

Levenson JM, O'Riordan KJ, Brown KD, Trinh MA, Molfese DL, Sweatt JD (2004). Regulation of histone acetylation during memory formation in the hippocampus. $J$ Biol Chem 279: 40545-40559.

Levenson JM, Sweatt JD (2005). Epigenetic mechanisms in memory formation. Nat Rev Neurosci 6: 108-118.

Levine AA, Guan Z, Barco A, Xu S, Kandel ER, Schwartz JH (2005). CREB-binding protein controls response to cocaine by acetylating histones at the fosB promoter in the mouse striatum. Proc Natl Acad Sci USA 102: 19186-19191.

Li CY, Mao X, Wei L (2008). Genes and (common) pathways underlying drug addiction. PLoS Comput Biol 4: e2.

Li DH, Depoortere RY, Emmett-Oglesby MW (1994). Tolerance to the reinforcing effects of cocaine in a progressive ratio paradigm. Psychopharmacology (Berl) 116: 326-332.

Liu XY, Chu XP, Mao LM, Wang M, Lan HX, Li MH et al. (2006). Modulation of D2R-NR2B interactions in response to cocaine. Neuron 52: 897-909.

Liu XY, Mao LM, Zhang GC, Papasian CJ, Fibuch EE, Lan HX et al. (2009). Activity-dependent modulation of limbic dopamine D3 receptors by CaMKII. Neuron 61: 425-438.

Lu L, Hope BT, Dempsey J, Liu SY, Bossert JM, Shaham Y (2005). Central amygdala ERK signaling pathway is critical to incubation of cocaine craving. Nat Neurosci 8: 212-219.

Lunyak VV, Burgess R, Prefontaine GG, Nelson C, Sze SH, Chenoweth J et al. (2002). Corepressor-dependent silencing of chromosomal regions encoding neuronal genes. Science 298: 1747-1752.

McClung CA, Nestler EJ (2003). Regulation of gene expression and cocaine reward by CREB and DeltaFosB. Nat Neurosci 6: $1208-1215$.

McClung CA, Nestler EJ, Zachariou V (2005). Regulation of gene expression by chronic morphine and morphine withdrawal in the locus ceruleus and ventral tegmental area. J Neurosci 25: 6005-6015.

McGregor A, Roberts DC (1995). Effect of medial prefrontal cortex injections of SCH 23390 on intravenous cocaine self-administration under both a fixed and progressive ratio schedule of reinforcement. Behav Brain Res 67: 75-80.

Mima K, Deguchi S, Yamauchi T (2001). Characterization of $5^{\prime}$ flanking region of alpha isoform of rat $\mathrm{Ca}^{2+} /$ calmodulindependent protein kinase II gene and neuronal cell type specific promoter activity. Neurosci Lett 307: 117-121.

Nestler EJ (2001). Molecular basis of long-term plasticity underlying addiction. Nat Rev Neurosci 2: 119-128.

Nestler EJ, Kelz MB, Chen J (1999). DeltaFosB: a molecular mediator of long-term neural and behavioral plasticity. Brain Res 835: 10-17.

Oleson EB, Roberts DC (2009). Behavioral economic assessment of price and cocaine consumption following self-administration histories that produce escalation of either final ratios or intake. Neuropsychopharmacology 34: 796-804.

Olmstead MC, Lafond MV, Everitt BJ, Dickinson A (2001). Cocaine seeking by rats is a goal-directed action. Behav Neurosci 115: 394-402.

Parkinson JA, Olmstead MC, Burns LH, Robbins TW, Everitt BJ (1999). Dissociation in effects of lesions of the nucleus accumbens core and shell on appetitive pavlovian approach behavior and the potentiation of conditioned reinforcement and locomotor activity by D-amphetamine. J Neurosci 19: 2401-2411.

Paterson NE, Markou A (2003). Increased motivation for selfadministered cocaine after escalated cocaine intake. NeuroReport 14: 2229-2232.

Pich EM, Pagliusi SR, Tessari M, Talabot-Ayer D, Hooft van Huijsduijnen R, Chiamulera C (1997). Common neural substrates for the addictive properties of nicotine and cocaine. Science 275: 83-86.

Pokholok DK, Harbison CT, Levine S, Cole M, Hannett NM, Lee TI et al. (2005). Genome-wide map of nucleosome acetylation and methylation in yeast. Cell 122: 517-527.

Renthal W, Kumar A, Xiao G, Wilkinson M, Covington III HE, Maze I et al. (2009). Genome-wide analysis of chromatin regulation by cocaine reveals a role for sirtuins. Neuron 62: 335-348.

Renthal W, Maze I, Krishnan V, Covington III HE, Xiao G, Kumar A et al. (2007). Histone deacetylase 5 epigenetically controls behavioral adaptations to chronic emotional stimuli. Neuron 56: 517-529.

Renthal W, Nestler EJ (2008). Epigenetic mechanisms in drug addiction. Trends Mol Med 14: 341-350.

Richardson NR, Roberts DC (1996). Progressive ratio schedules in drug self-administration studies in rats: a method to evaluate reinforcing efficacy. J Neurosci Methods 66: 1-11.

Robledo P, Koob GF (1993). Two discrete nucleus accumbens projection areas differentially mediate cocaine self-administration in the rat. Behav Brain Res 55: 159-166.

Romieu P, Host L, Gobaille S, Sandner G, Aunis D, Zwiller J (2008). Histone deacetylase inhibitors decrease cocaine but not sucrose self-administration in rats. J Neurosci 28: 9342-9348.

Steffan JS, Bodai L, Pallos J, Poelman M, McCampbell A, Apostol BL et al. (2001). Histone deacetylase inhibitors arrest polyglutamine-dependent neurodegeneration in Drosophila. Nature 413: 739-743.

Sun J, Wang L, Jiang B, Hui B, Lv Z, Ma L (2008). The effects of sodium butyrate, an inhibitor of histone deacetylase, on the cocaine- and sucrose-maintained self-administration in rats. Neurosci Lett 441: 72-76.

Thiriet N, Aunis D, Zwiller J (2000). C-fos and egr-1 immediateearly gene induction by cocaine and cocaethylene in rat brain: a comparative study. Ann NY Acad Sci 914: 46-57. 
Tobimatsu T, Fujisawa H (1989). Tissue-specific expression of four types of rat calmodulin-dependent protein kinase II mRNAs. J Biol Chem 264: 17907-17912.

Tsankova N, Renthal W, Kumar A, Nestler EJ (2007). Epigenetic regulation in psychiatric disorders. Nat Rev Neurosci 8: 355-367. Tsankova NM, Kumar A, Nestler EJ (2004). Histone modifications at gene promoter regions in rat hippocampus after acute and chronic electroconvulsive seizures. J Neurosci 24: 5603-5610.
Winstanley CA, LaPlant Q, Theobald DE, Green TA, Bachtell RK, Perrotti LI et al. (2007). DeltaFosB induction in orbitofrontal cortex mediates tolerance to cocaine-induced cognitive dysfunction. J Neurosci 27: 10497-10507.

Yao WD, Gainetdinov RR, Arbuckle MI, Sotnikova TD, Cyr M, Beaulieu JM et al. (2004). Identification of PSD-95 as a regulator of dopamine-mediated synaptic and behavioral plasticity. Neuron 41: 625-638.

Supplementary Information accompanies the paper on the Neuropsychopharmacology website (http://www.nature.com/npp) 